\title{
Comparison of Oceanic Multisatellite Precipitation Data from Tropical Rainfall Measurement Mission and Global Precipitation Measurement Mission Datasets with Rain Gauge Data from Ocean Buoys
}

\author{
QIAOYAN WU \\ State Key Laboratory of Satellite Ocean Environment Dynamics, Second Institute of Oceanography, \\ Ministry of Natural Resources, Hangzhou, Zhejiang Province, and Institute of Oceanography, \\ Shanghai Jiao Tong University, Shanghai, China \\ YILEI WANG \\ State Key Laboratory of Satellite Ocean Environment Dynamics, Second Institute of Oceanography, \\ Ministry of Natural Resources, Hangzhou, Zhejiang Province, China
}

(Manuscript received 3 September 2018, in final form 6 March 2019)

\begin{abstract}
Three satellite-derived precipitation datasets [the Tropical Rainfall Measuring Mission Multisatellite Precipitation Analysis (TMPA) dataset, the NOAA Climate Prediction Center morphing technique (CMORPH) dataset, and the newly available Integrated Multisatellite Retrievals for Global Precipitation Measurement (IMERG) dataset] are compared with data obtained from 55 rain gauges mounted on floating buoys in the tropics for the period 1 April 2014-30 April 2017. All three satellite datasets underestimate low rainfall and overestimate high rainfall in the tropical Pacific Ocean, but the TMPA dataset does this the most. In the high-rainfall (higher than $4 \mathrm{~mm} \mathrm{day}^{-1}$ ) Atlantic region, all three satellite datasets overestimate low rainfall and underestimate high rainfall, but the IMERG dataset does this the most. For the Indian Ocean, all three rainfall satellite datasets overestimate rainfall at some gauges and underestimate it at others. Of these three satellite products, IMERG is the most accurate in estimating mean precipitation over the tropical Pacific and Indian Oceans, but it is less accurate over the tropical Atlantic Ocean for regions of high rainfall. The differences between the three satellite datasets vary by region and there is a need to consider uncertainties in the data before using them for research.
\end{abstract}

\section{Introduction}

Three-quarters of the heat energy supplied to the atmosphere comes from the latent heat released by precipitation, and two-thirds of all precipitation falls in the tropics (Tao et al. 2007). Variations in large-scale patterns of rainfall and the associated releases of energy affect global circulation. Satellite remote sensing instruments have provided much information on precipitation for use in research and other applications around the world over the past few years.

Global satellite-based rainfall products include microwaveonly, calibrated infrared (IR), and microwave plus IR observations from various satellite missions, and have used a variety of merged techniques (Sorooshian et al. 2000; Kuligowski 2002; Kidd et al. 2003; Joyce et al. 2004; Huffman et al. 2007; Kubota et al. 2007; Huffman et al. 2017a,b). Microwave sensors can "see" through cloud systems but

\footnotetext{
Corresponding author: Dr. Qiaoyan Wu, qwu@sio.org.cn
}

only at a low temporal/spatial resolution, while IR-only can be used to sense the cloud top temperature but at a high temporal and spatial resolution. Low-frequency microwave measurements can be used to detect thermal emissions from rainfall, while at higher frequencies, microwaves can be used to detect scattering caused by ice particles in precipitation. Different measurement accuracies, sampling frequencies, and merged methodologies reveal marked differences between different precipitation products. The development of better products requires more accurate and more frequent microwave measurements within a unified observational framework (Hou et al. 2014).

Multisatellite rainfall products were largely based on algorithms and validation with Tropical Rainfall Measuring Mission (TRMM) data before this stopped being available. TRMM Multisatellite Precipitation Analysis (TMPA), for example, is a calibration-based sequential scheme for combining estimates of precipitation made by multiple satellites (Huffman et al. 2007, 2010). 
Another example is the Climate Prediction Center (CPC) morphing technique (CMORPH), which produces a temporally and spatially complete precipitation field by morphing passive microwave data using motion vectors derived from half-hourly geostationary satellite IR images (Joyce et al. 2004; Xie et al. 2017).

The Global Precipitation Measurement (GPM) mission Core Observatory was built upon the success of the TRMM satellite and was launched on 27 February 2014 by the Japanese Aerospace Exploration Agency and the U.S. National Aeronautics and Space Administration (NASA). The GPM mission is an international network of satellites intended to provide the next generation of global rain and snow observation systems (Hou et al. 2014). GPM allows markedly better spatial resolution and coverage than TRMM. The Integrated Multisatellite Retrievals for GPM (IMERG) products have yielded improvements to both spatial and temporal resolutions (Huffman et al. 2017a,b).

It is important to characterize the systematic differences between rainfall products based on TRMM and GPM data during the transition from TMPA to IMERG products. Liu (2016) compared the TMPA and the GPM Day 1 IMERG algorithm (version 03) monthly products and found that the systematic differences were far lower over land than over the oceans because the products use similar gauge adjustments over land. The rainfall over the ocean was lower in the IMERG product than in the TMPA product for all rainfall intensities. The rainfall over land was higher in the IMERG product than in the TMPA product at low rainfall rates and lower in the IMERG product than in the TMPA product at high rainfall rates. Although the rainfall over the ocean was less in the IMERG product than in the TMPA product, Liu et al. (2018) found that the amplitude of the response of the rainfall to oceanic eddies was much stronger in the IMERG product than in the TMPA or CMORPH datasets. There have been a number of attempts to make comparisons between TMPA and IMERG data over land. Tang et al. (2016) validated the IMERG and TMPA products over mainland China, for example, and Murali Krishna et al. (2017) compared two datasets for the Indian subcontinent. Wang et al. (2017) compared data for eight typhoons over the Chinese coast in 2014 and 2015 from the IMERG final run and from the TMPA dataset with data obtained from rain gauges. In all these studies, rainfall was found to be estimated more accurately by IMERG than by TMPA products.

Over land, precipitation can be measured using rain gauges and radar, but over the oceans in situ precipitation data are provided by ships and by a limited number of rain gauges on networks of ocean buoys. Precipitation is highly variable in space and time, and in situ precipitation observations over the oceans have limited applicability for global- and regional-scale applications. Satellite-based retrieval of precipitation is now more reliable, and can provide consistent and homogeneous data with global coverage. However, the measurement of precipitation over the oceans has not yet been validated fully, in the way that it has beenover land. There is a clear need for ground-truthing of data via observations or other measurements, which are of clear use for comparison with and validation of satellite products (e.g., Bowman et al. 2003, 2009; Sapiano and Arkin 2009; Prakash et al. 2013; Prakash and Gairola 2014; Burdanowitz et al. 2017). Rain gauges provide direct physical measurements of precipitation and are therefore considered to provide the most accurate measurements (Qin et al. 2014; Murali Krishna et al. 2017). Comparisons of in situ measurements made in the Kuroshio Extension region with rainfall measurements made using Kuroshio Extension Observatory buoys have shown that mean rainfall and the distribution of rainfall intensity were better estimated using IMERG than TMPA or CMORPH data (Liu et al. 2018). Comparisons of moored buoy observations over the northern Indian Ocean with IMERG and TMPA for the period March 2014 to December 2015 have shown that IMERG is more reliable than TMPA at a daily scale (Prakash et al. 2018). However, it is not yet fully understood how IMERG data compare with TMPA and CMORPH data for rainfall over other ocean regions. In this study, three satellite ocean algorithms for estimating precipitation, all based on TRMM and GPM data, are compared with data collected from rain gauges mounted on ocean buoys, the accuracy of the satellite precipitation data is assessed, and the biases of the different observational systems are noted.

The paper is organized as follows. Section 2 contains a description of three different satellite datasets, and the results are presented in section 3 , in which three runs of IMERG are first compared with data obtained from buoys. Three satellite ocean precipitation estimation algorithms based on TRMM and GPM data are then compared with the same ocean buoy data, and a global intercomparison of the three products is given. Section 4 contains a summary of the major findings.

\section{Data}

\section{a. Satellite precipitation datasets}

The TMPA algorithm combines multiple independent estimates of precipitation made using various passive microwave measurements collected by low earth orbit satellites with microwave-adjusted merged geostationary IR estimates and monthly accumulated rain gauge analysis data from the Global Precipitation Climatology Centre (GPCC) (Huffman et al. 2007, 2010, 2015). The passive microwave measurements include TRMM Microwave 
Imager (TMI) data, Advanced Microwave Scanning Radiometer for Earth Observing Systems (AMSR-E) data, Special Sensor Microwave Imager (SSMI) data, Special Sensor Microwave Imager/Sounder (SSMIS) data, Advanced Microwave Sounding Unit (AMSU) data, and Microwave Humidity Sounder (MHS) data. The production of TMPA 3B42 data estimates follows four stages. First, microwave precipitation estimates are calibrated and combined. IR precipitation estimates are then created using a monthly matched microwave-IR histogram matching procedure. The microwave and IR estimates are then combined to fill any gaps in the 3-hourly microwave field dataset. Finally, the multisatellite data are combined with the GPCC monthly gauge analysis data (Huffman et al. 2007). TMPA 3B42 data (version 7) are available between $50^{\circ} \mathrm{S}$ and $50^{\circ} \mathrm{N}$, with a horizontal resolution of $0.25^{\circ} \times 0.25^{\circ}$ every $3 \mathrm{~h}$ from 1998 to the present.

Like the TMPA dataset, the CMORPH dataset is based on passive microwave measurements obtained from SSMIS data, AMSU data, AMSR-E data, and TMI data. However, CMORPH uses a rather different approach from the TMPA system, in order to take advantage of the high temporal resolution of the geostationary IR observations (Joyce et al. 2004). Motion vectors for cloud systems are first defined from consecutive geostationary IR images using cross correlation. Precipitation analyses are then produced at 30 -min intervals for an $8 \mathrm{~km} \times 8 \mathrm{~km}$ grid covering the globe by propagating the precipitating cloud clusters identified from instantaneous passive microwave estimates along the cloud motion vectors. The purely satellite-based CMORPH precipitation estimates (raw CMORPH data) were recently reprocessed and corrected for bias (Xie et al. 2017). The raw CMORPH data were corrected for bias by matching the probability density functions (PDFs) to the results of the CPC daily gauge analysis over land, and then adjusting the data to agree with the Global Precipitation Climatology Project (GPCP) pentad merged analysis data for precipitation over the oceans. The bias-corrected CMORPH data represent the precipitation magnitudes, spatial distribution patterns, and temporal variations over the global domain better than the uncorrected CMORPH data (Xie et al. 2017). The reprocessed CMORPH data were termed "version 1.0," and had a horizontal resolution of $0.25^{\circ} \times 0.25^{\circ}$ between $60^{\circ} \mathrm{N}$ and $60^{\circ} \mathrm{S}$ every $3 \mathrm{~h}$ between January 1998 and the present.

The IMERG product unifies precipitation data obtained from the GPM constellation. The GPM Core Observatory satellite has a Dual-Frequency Precipitation Radar (DPR) and GPM Microwave Imager (GMI). The dual-band precipitation radar gives a better estimate of the sizes of precipitation particles and covers a wider range of precipitation rates than the single-band radar on the TRMM satellite. The TMI system has 9 microwave channels but the GMI has 13. Six channels in the GPM with frequencies higher than TMI lead to the GMI system have a higher resolution than the TMI system. The IMERG dataset has a finer spatial resolution $\left(0.1^{\circ} \times 0.1^{\circ}\right)$ and covers a wider range of precipitation types (including light rain and snow) than the TMPA dataset. There are more sensors in the IMERG system than in the TMPA system. The IMERG dataset uses the TMI (IMERG datasets prior to version 05), AMSR, SSM/I, SSMIS, AMSU, and MHS passive microwave measurements that are used in the TMPA dataset, and additionally DPR, GMI, Sounder for Atmospheric Profiling of Humidity in the Inter tropics by Radiometry (SAPHIR), and Advanced Technology Microwave Sounder (ATMS) passive microwave measurements (Huffman et al. 2017b). Data from the different sensors used in the TMPA and IMERG datasets suggest that passive microwave precipitation estimates made using TMPA and IMERG may be appreciably different.

The GPM IMERG algorithm has all the advantages of the TMPA, CMORPH, and Precipitation Estimation from Remotely Sensed Information Using Artificial Neural Networks-Cloud Classification System (PERSIANN-CCS). The rain gauge analysis used was the same as that used in the TMPA by the GPCC. The integration framework for the IMERG technique was based on the Kalman filter version of the CMORPH technique (Joyce and Xie 2011) combined with the intercalibration and bias-adjustment algorithms used in the TMPA method (Huffman et al. 2007) and the geostationary IR estimation method used in the Precipitation Estimation from Remotely Sensed Information using Artificial Neural Networks system (Hsu et al. 1997). It contains monthly and half-hourly datasets from a final run (about 2.5 months after observation time), an early run (4-5 h after observation time), and a late run ( $14 \mathrm{~h}$ after observation time) (Huffman et al. 2017c). Here, estimates of precipitation obtained from IMERG version 05 for all three runs are compared first, and then the final run product (Huffman et al. 2017d) is compared with the TMPA, CMORPH, and gauge data. Version 05 of IMERG comprises restricted MHS and ATMS swaths, and no longer includes TMI, reflecting the reduced amount of microwavebased data contained in version 05 compared to previous versions (Huffman et al. 2017d). It had been demonstrated that at a global scale, final runs of both version 04 and version 05 showed significant differences and improvements compared with version 03 (Wang et al. 2018). IMERG version 05 products are available at half-hour intervals from 12 March 2014 to the present, from $60^{\circ} \mathrm{S}$ to $60^{\circ} \mathrm{N}$.

\section{b. Rain gauge data}

In situ measurements of precipitation over the oceans are available as a subset of the Tropical AtmosphereOcean (TAO) buoy array dataset for the tropical Pacific 
(a) Pacific Ocean

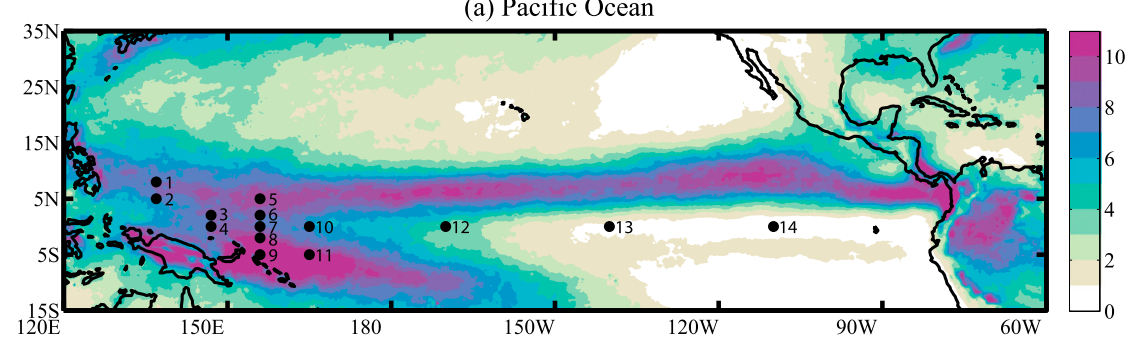

(b) Atlantic Ocean

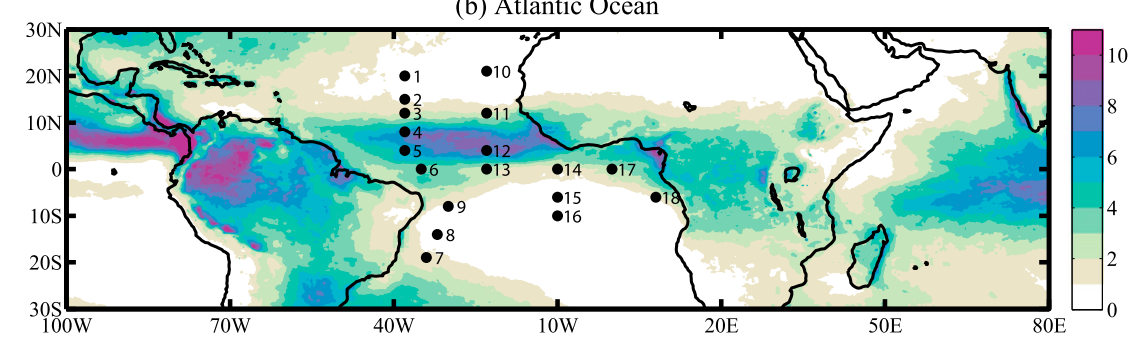

(c) Indian Ocean

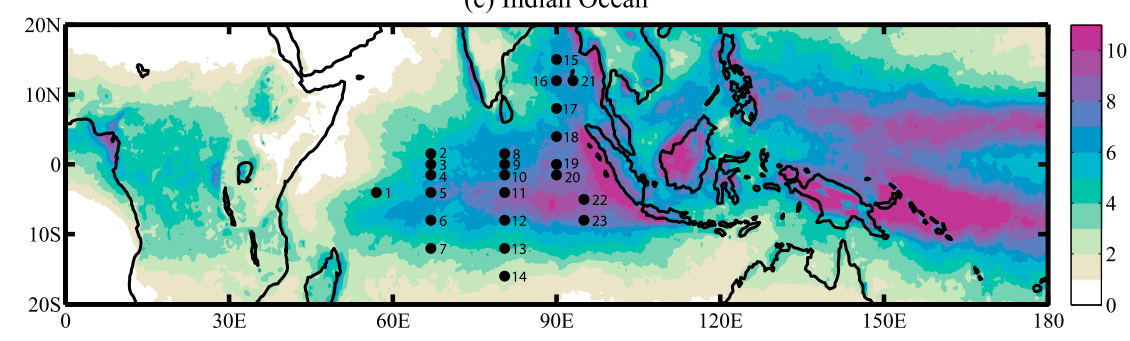

FIG. 1. Locations of the (a) TAO, (b) PIRATA, and (c) RAMA rain gauge buoys used in the study. The colors represent the mean rainfall rates from the TMPA dataset for the period 1 Apr 2014-30 Apr 2017.

(Hayes et al. 1991; McPhaden et al. 1998; Serra et al. 2001; Serra and McPhaden 2004), the Pilot Research Moored Array in the Atlantic (PIRATA) buoy array dataset for the tropical Atlantic (McPhaden et al. 1998; Serra et al. 2001; Serra and McPhaden 2004), and the Research Moored Array for African-AsianAustralian Monsoon Analysis and Prediction (RAMA) dataset for the tropical Indian Ocean (McPhaden et al. 2009). Rainfall rates were inferred from changes in the water volumes in the gauges, but noise in the volume measurements could have led to small positive or negative discrepancies in terms of measurement compared with actual rainfall (Serra et al. 2001). Rain gauges are generally assumed to underestimate rainfall due to wind effects (Serra et al. 2001).

In this study, a comparative analysis is performed using overlapping rain gauge measurement periods and the three satellite-derived datasets described above, for the period 1 April 2014-30 April 2017. The locations of the rain gauges are shown in Fig. 1. Data from 14 buoys in the Pacific Ocean, 18 buoys in the Atlantic Ocean, and 23 buoys in the Indian Ocean with at least six months of data were used. The gauges were numbered for reference. The mean rainfall values from the TMPA data for 1 April 2014-30 April 2017 are also shown in Fig. 1. The buoys are mostly located in areas of high rainfall in the tropics, including the Pacific warm pool, the South Pacific convergence zone (SPCZ), the Atlantic intertropical convergence zones (ITCZs), and the Indian Ocean. Buoys in low-rainfall areas were located mostly in the Atlantic.

The rain gauge data available for each TAO, PIRATA, and RAMA buoy are shown in Fig. 2. Data from all the gauges were intermittent, with relatively long gaps. The total number of days for which data for each gauge was available is shown in Fig. 2.

\section{Results}

\section{a. Comparison of IMERG version 05 products with gauge data}

IMERG provides three kinds of products, namely, early, late, and final runs (Huffman et al. 2017c). Early 
(a) TAO

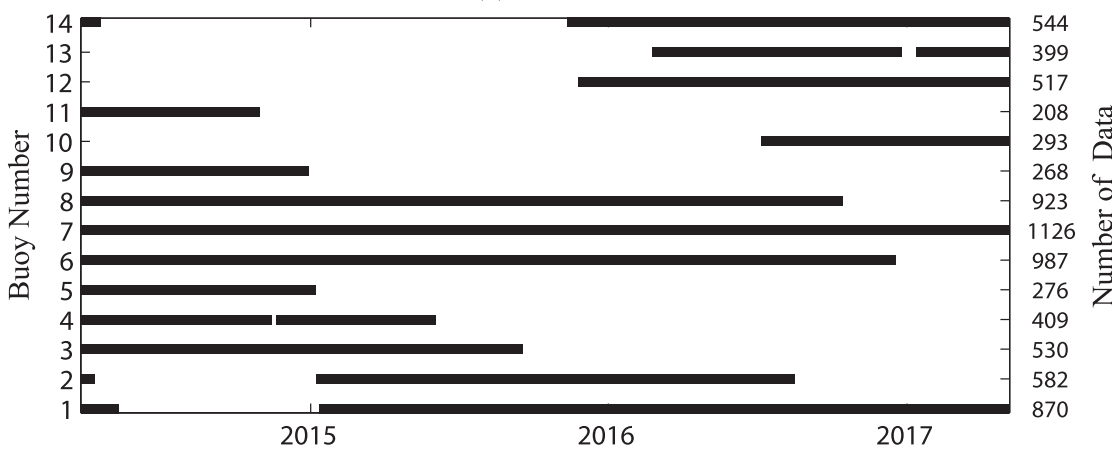

(b) PIRATA

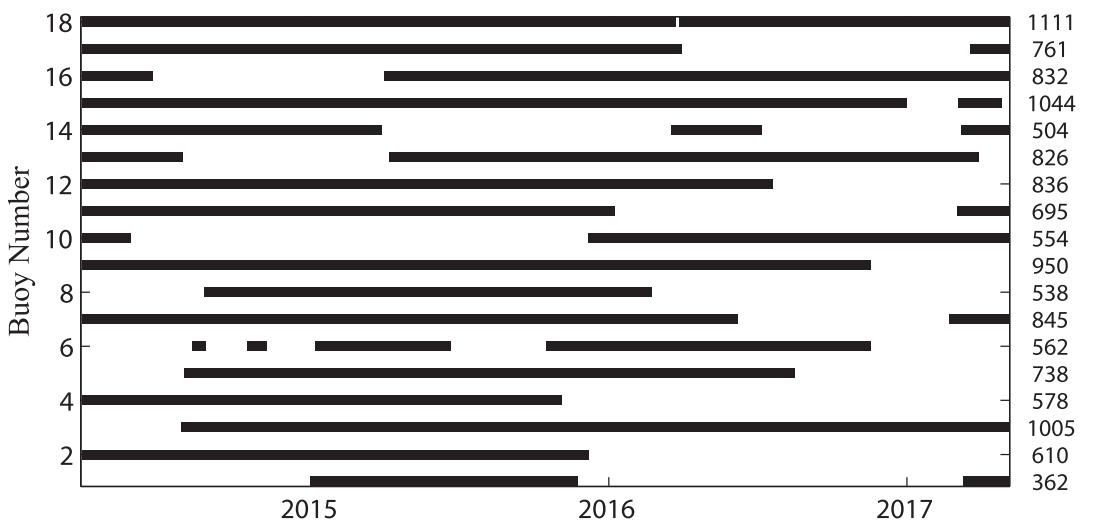

(c) RAMA

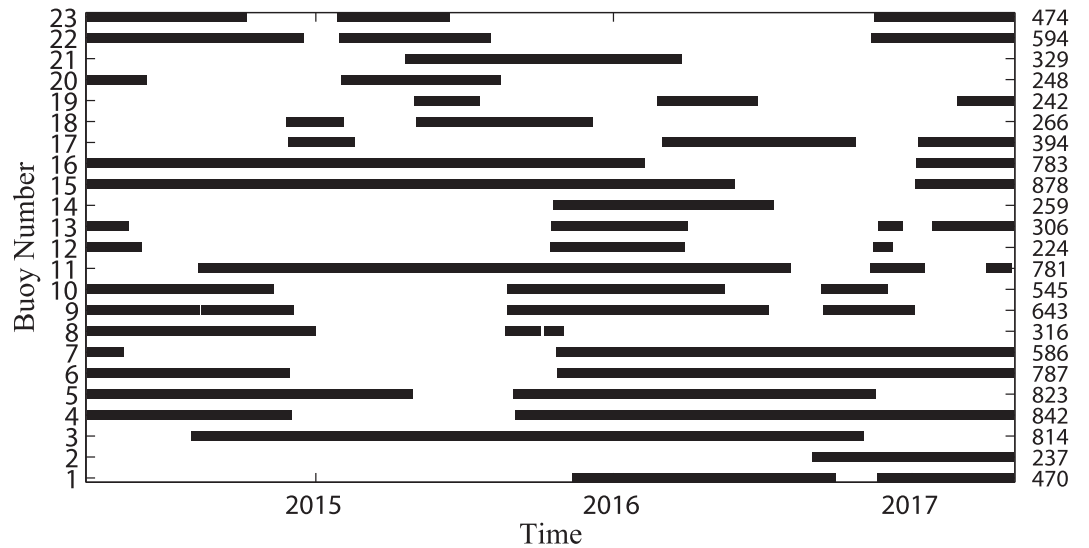

FIG. 2. Availability of (a) TAO, (b) PIRATA, and (c) RAMA buoy data for each location. The number of days for which data were available for each buoy is shown on the righthand side.

run and late run products are produced in near-real time and calibrated using climatological coefficients varying by month and location, while final run products are produced post-real time following gauge adjustments, in order to be consistent with GPCC precipitation data (Huffman et al. 2017a). Final run products generally have greater accuracy, over land. Three runs of IMERG over the oceans have not yet been fully validated.
Therefore, three runs of IMERG are first compared with data obtained from buoys.

The relationships between the time-averaged gauge data and three $0.1^{\circ} \times 0.1^{\circ}$ grid IMERG version 05 products in the tropical Pacific, Atlantic, and Indian Oceans are shown in Fig. 3. Dashed lines indicate oneto-one relationships. Lines were fitted to the data using the least squares method, and the results are summarized 
(a) Pacific Ocean

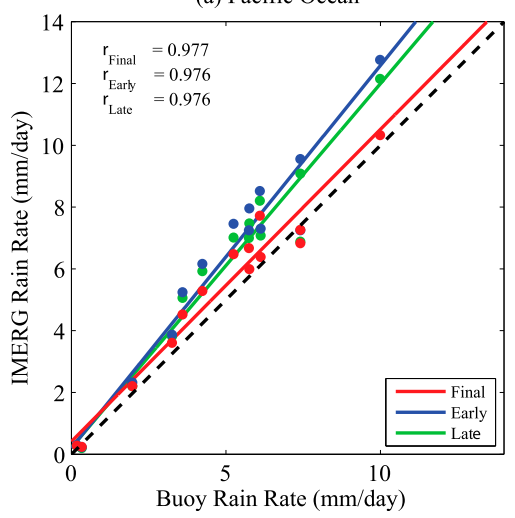

(b) Atlantic Ocean

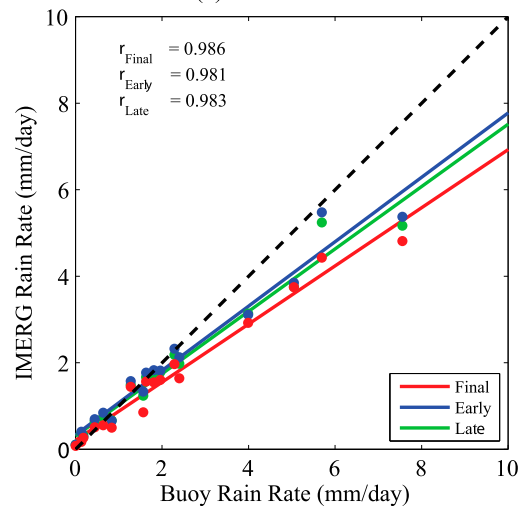

(c) Indian Ocean

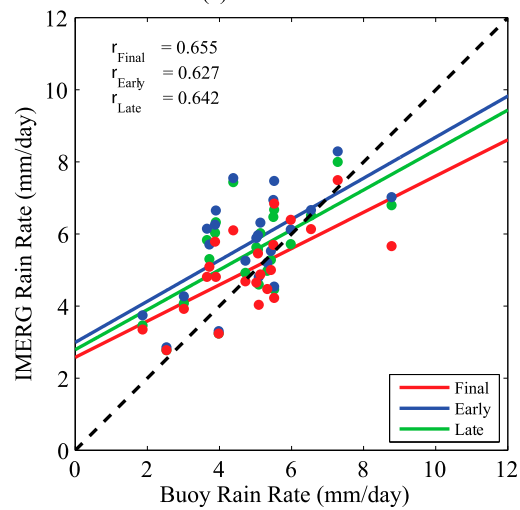

FIG. 3. Scatterplots of the time-mean rainfall rates for each gauge location measured by the buoy rain gauges and final run (red line), early run (blue line), and late run (green line) IMERG version 05 products for the (a) Pacific Ocean, (b) Atlantic Ocean, and (c) Indian Ocean. Dashed lines indicate one-to-one relationships.

in Table 1. For all three tropical oceans, the mean IMERG final run rainfall rates are the lowest and the early run rainfall rates are the highest. The three IMERG products were well correlated with the buoy data for all three oceans. The correlations for the three IMERG runs are nearly identical, both over the Pacific and over the Atlantic, and show only a small difference for the tropical Indian Ocean. All three IMERG products overestimated the rainfall over the tropical Pacific, and the IMERG final run products fitted the gauge data better than the other two products (Fig. 3a). In contrast, over the tropical Atlantic all three IMERG products underestimated the rainfall, and the IMERG early run products matched the gauge data better than the other two products (Fig. 3b). In the Indian Ocean (Fig. 3c), none of the three IMERG products matched the gauge data as well as in the tropical Pacific and Atlantic oceans, and the correlation coefficients for the relationships between all three IMERG products and the buoy data were relatively small. In the Indian Ocean, the IMERG products underestimated the rainfall for some gauges and overestimated the rainfall for others.

\section{b. Comparison of satellite and gauge data}

Satellite instruments and gauges measure rainfall in very different ways. Satellite instruments essentially make area-averaged measurements, whereas gauges only make point measurements. Satellite and gauge data are generally compared by averaging the data over space and time (Bowman 2005; Bowman et al. 2009). We calculated rainfall statistics for all three satellite products using area-averaged rainfall over areas between $0.25^{\circ} \times 0.25^{\circ}$ and $2.5^{\circ} \times 2.5^{\circ}$ square boxes centered on buoy locations (Fig. 4). The differences between satellite and gauge measurements were in general not sensitive to changes in the averaging area except for those cases where buoys were located in regions with rates of rainfall very different from those in adjacent regions. For example, the satellite and gauge area-averaged rainfalls were more different for the $2.5^{\circ} \times 2.5^{\circ}$ square box centered on TAO buoys $9,11,13$, and 14 in the Pacific Ocean, and PIRATA buoys 4,12 , and 13 , than for $0.5^{\circ} \times 0.5^{\circ}$ to $1.0^{\circ} \times 1.0^{\circ}$ boxes with the same center. For those buoys, the differences increase as the averaging area increases to $2.5^{\circ} \times 2.5^{\circ}$ square box. Hereafter, we refer to satellite estimates averaged using a $0.5^{\circ} \times$ $0.5^{\circ}$ grid compared with the buoy data.

The relationships between the time-mean gauge data and three satellite estimates averaged using a $0.5^{\circ} \times 0.5^{\circ}$ grid in the tropical Pacific, Atlantic, and Indian Oceans are shown in Fig. 5. As shown in Fig. 5a, the buoy data were very well correlated with the satellite precipitation data for the tropical Pacific. Lines were fitted to the data using the least squares method, and the results are summarized in Table 2. The correlation coefficients for the relationships between the buoy data and the IMERG, TMPA, and CMORPH data for the Pacific were $0.975,0.981$, and 0.956 , respectively. The IMERG data matched the gauge data better than the other satellite datasets, and the slope of the line fitted for the gauge versus IMERG data was 1.005. In fact, the slopes of the relationships between all three satellite rainfall datasets and the buoy data were all $>1$, suggesting that all three satellite products overestimated rainfall. As for the Pacific, the buoy data were well correlated with all three satellite datasets for the tropical Atlantic (Fig. 5b). The correlation coefficients for the relationships between the buoy data and the IMERG, TMPA, and CMORPH data were $0.989,0.991$, and 0.979 , respectively. Unlike 
TABLE 1. Least squares fitting parameters for the relationships between final run, early run, and late run IMERG version 05 data and buoy gauge data for the three ocean basins.

\begin{tabular}{|c|c|c|c|c|c|c|c|c|c|}
\hline & \multicolumn{3}{|c|}{ Pacific Ocean } & \multicolumn{3}{|c|}{ Atlantic Ocean } & \multicolumn{3}{|c|}{ Indian Ocean } \\
\hline & Final & Early & Late & Final & Early & Late & Final & Early & Late \\
\hline Slope & 1.010 & 1.238 & 1.178 & 0.672 & 0.744 & 0.721 & 0.5032 & 0.569 & 0.554 \\
\hline Intercept & 0.413 & 0.202 & 0.202 & 0.205 & 0.332 & 0.303 & 2.576 & 2.992 & 2.790 \\
\hline Correlation & 0.977 & 0.976 & 0.976 & 0.986 & 0.981 & 0.983 & 0.655 & 0.627 & 0.642 \\
\hline
\end{tabular}

for the Pacific, however, the IMERG and CMORPH data underestimated the rainfall for the Atlantic. The IMERG data underestimated the rainfall most for the areas occupied by four buoys (PIRATA buoys 4, 5, 6 , and 12) in areas with relatively high rainfall in the Atlantic (high rainfall is herein defined as being greater than $\left.4 \mathrm{~mm} \mathrm{day}^{-1}\right)$. The intercepts for the lines fitted to the relationships between the buoy data and all three satellite datasets were close to zero. The correlation coefficients for the lines fitted to the relationships between the buoy data and all three satellite datasets were lower for the Indian Ocean than

(a) Pacific Ocean

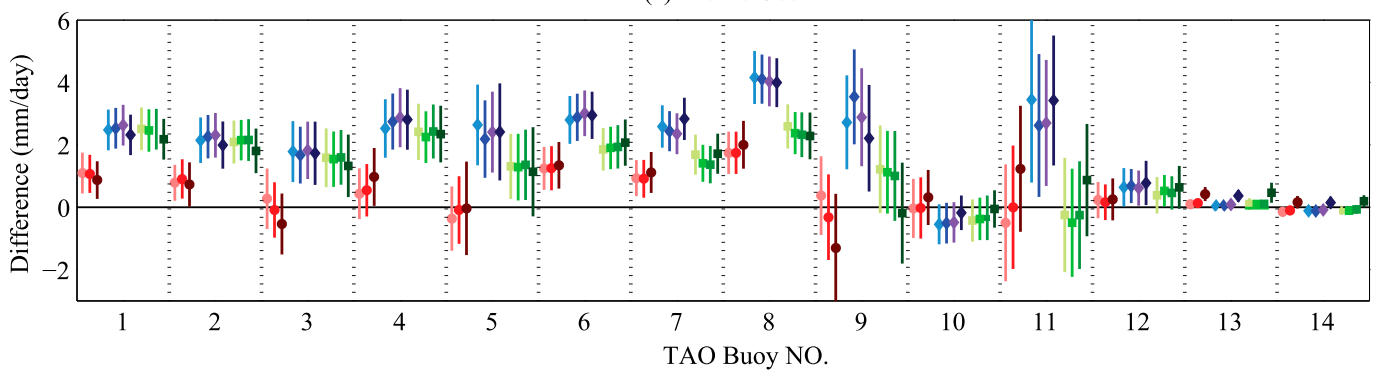

(b) Atlantic Ocean

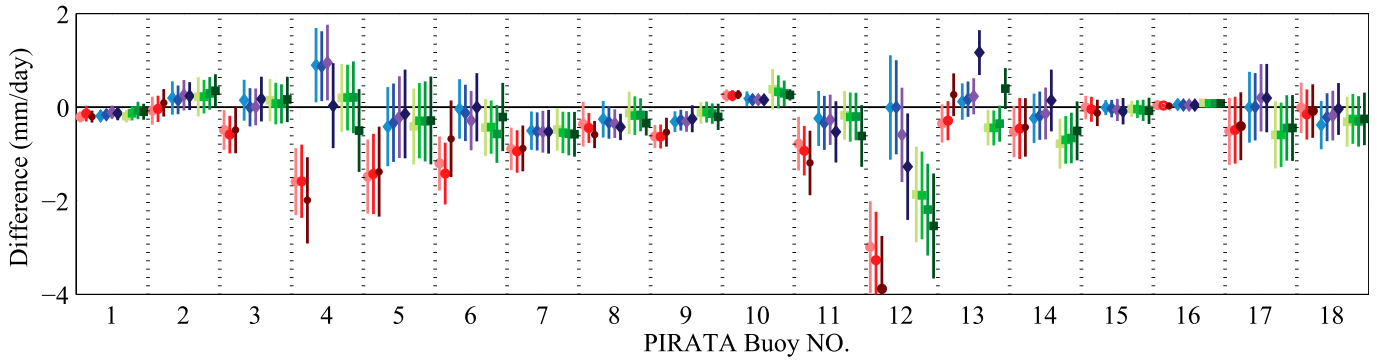

(c) Indian Ocean

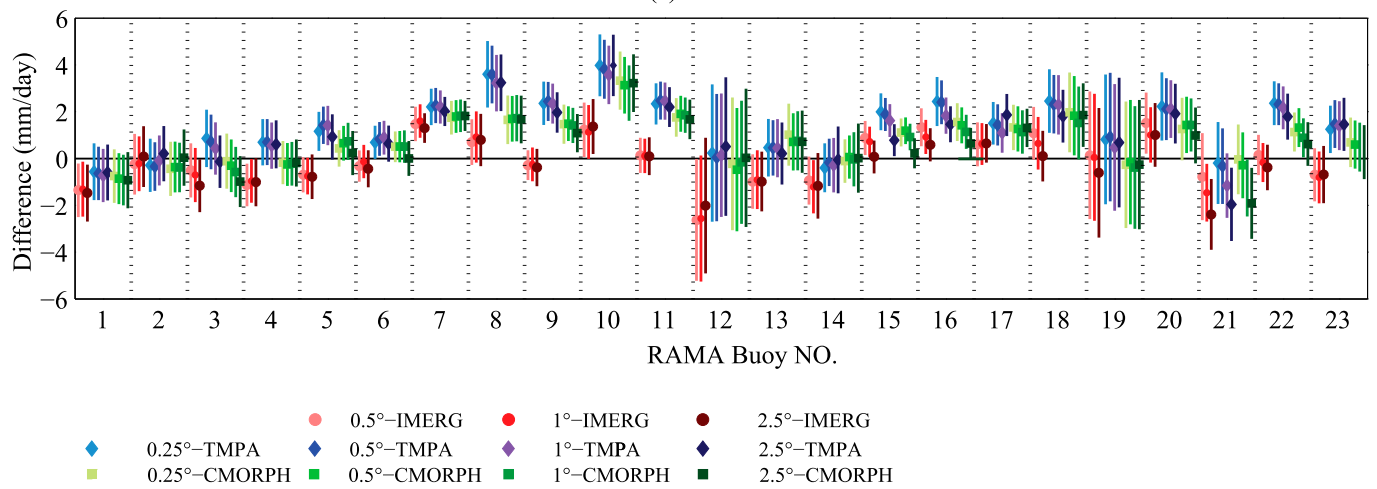

FIG. 4. Differences (satellite minus buoy) between the mean rainfall derived by averaging over different areas from the IMERG dataset and buoy data (red circles), the TMPA dataset and buoy data (blue diamonds), and the CMORPH dataset and buoy data (green squares) for the (a) Pacific Ocean, (b) Atlantic Ocean, and (c) Indian Ocean. Each bar represents the $95 \%$ confidence interval of the mean difference. 
(a) Pacific Ocean

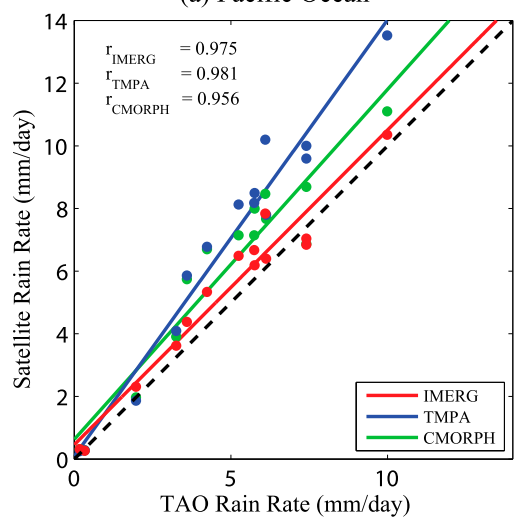

(b) Atlantic Ocean

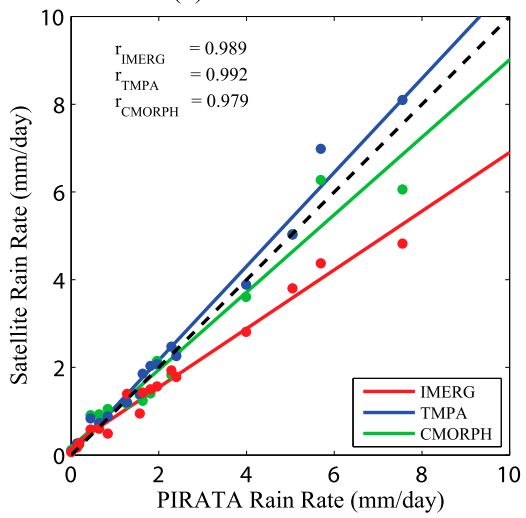

(c) Indian Ocean

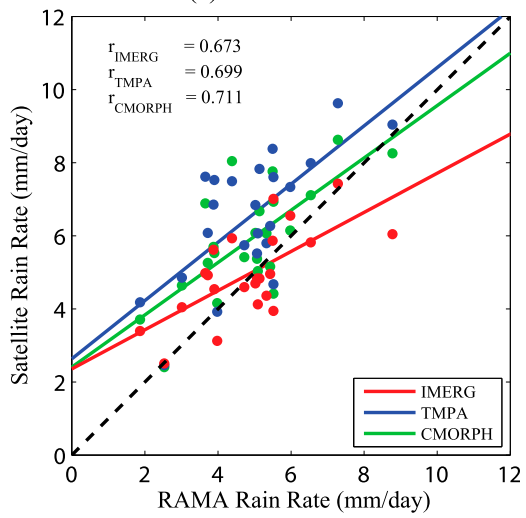

FIG. 5. Scatterplots of the time-mean rainfall rates for each gauge location measured by the buoy rain gauges and three satellite products for the (a) Pacific Ocean, (b) Atlantic Ocean, and (c) Indian Ocean. Dashed lines show one-to-one relationships.

for the Pacific and Atlantic Oceans (Fig. 5c). The correlation coefficients for the lines fitted to the relationships between the buoy data and the IMERG, TMPA, and CMORPH datasets were 0.673, 0.699, and 0.711, respectively. Unlike for the Pacific and Atlantic, the intercepts for the lines fitted to the relationships between the buoy data and each of the three satellite datasets for the Indian Ocean were not close to zero. For all three tropical oceans, the TMPA data systematically overestimated rainfall, and the lowest and highest regression slopes were for the IMERG and TMPA retrieval data, respectively (Fig. 5).

The mean differences between the satellite and buoy data relative to the mean buoy values are shown in Fig. 6. For the Pacific Ocean, the relative differences were mostly in the range $20 \%-60 \%$. For the high-rainfall region, the differences between the buoy measurements and the IMERG daily data were smaller than the differences between the buoy measurements and the other satellite rainfall datasets (Fig. 6a). For the low-rainfall region (TAO buoys 13 and 14), however, the IMERG data were no better than the other satellite datasets. For the high-rainfall regions in the Atlantic Ocean, the differences between the buoy measurements and the IMERG daily data were generally larger than the differences between the buoy measurements and the other satellite rainfall datasets (Fig. 6b). All three satellite rainfall datasets had large relative differences from the buoy measurements for the low-rainfall region. The differences between the PIRATA buoy 1 measurements and the daily IMERG, TMPA, and CMORPH data were $-152 \%,-117 \%$, and $-96 \%$, respectively. The differences between the data obtained from PIRATA buoys 10 and 16 and the daily IMERG, TMPA, and CMORPH data are up to several thousand percent, values that were too large to include in Fig. 6b. Because the absolute differences between the data from PIRATA buoys 10 and 16 and the satellite data were small, as shown in Fig. 4b, the large relative differences were in fact caused by low mean gauge values. For the Indian Ocean (Fig. 6c), rainfall was underestimated and overestimated at different places for all three satellite datasets. As for the Indian Ocean, the absolute differences between the buoy measurements and the IMERG daily data were generally smaller than the absolute differences between the buoy measurements and the other satellite rainfall datasets, indicating that the IMERG data yielded more accurate estimated mean precipitation over the tropical Indian oceans than the other satellite datasets.

The difference between the rainfall data from a satellite and a gauge typically decreases as the averaging time increases (Bowman 2005). Tables 3-5 show the relative mean square error between each $0.5^{\circ} \times 0.5^{\circ}$

TABLE 2. Least squares fitting parameters for the relationships between the three satellite products and buoy gauge data for the three ocean basins.

\begin{tabular}{|c|c|c|c|c|c|c|c|c|c|}
\hline & \multicolumn{3}{|c|}{ Pacific Ocean } & \multicolumn{3}{|c|}{ Atlantic Ocean } & \multicolumn{3}{|c|}{ Indian Ocean } \\
\hline & IMERG & TMPA & CMORPH & IMERG & TMPA & CMORPH & IMERG & TMPA & $\overline{\mathrm{CMORPH}}$ \\
\hline Slope & 1.005 & 1.393 & 1.117 & 0.670 & 1.071 & 0.884 & 0.536 & 0.797 & 0.716 \\
\hline Intercept & 0.458 & 0.088 & 0.628 & 0.205 & 0.02 & 0.179 & 2.357 & 2.633 & 2.404 \\
\hline Correlation & 0.975 & 0.981 & 0.956 & 0.989 & 0.991 & 0.979 & 0.673 & 0.699 & 0.711 \\
\hline
\end{tabular}


(a) Pacific Ocean

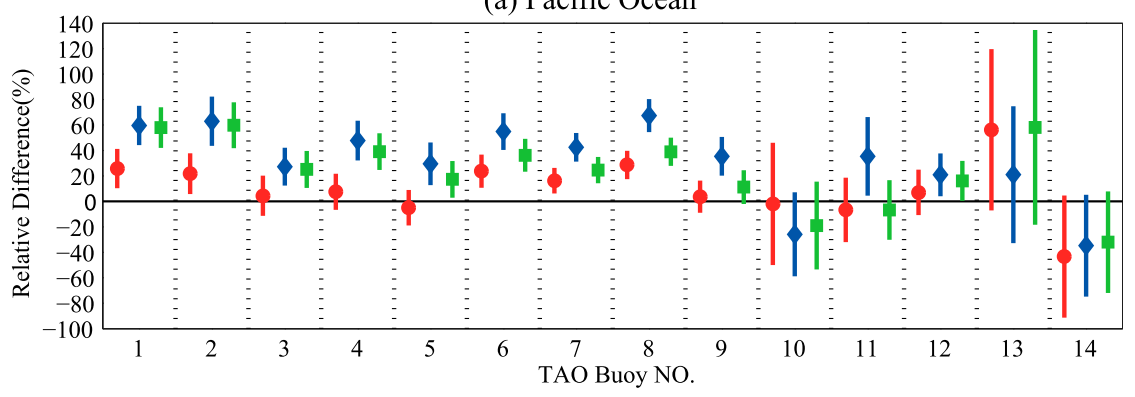

(b) Atlantic Ocean

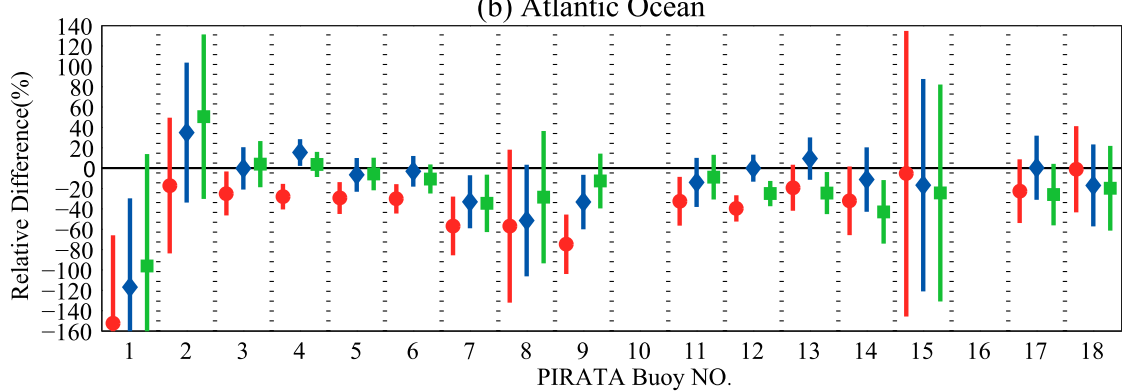

(c) Indian Ocean

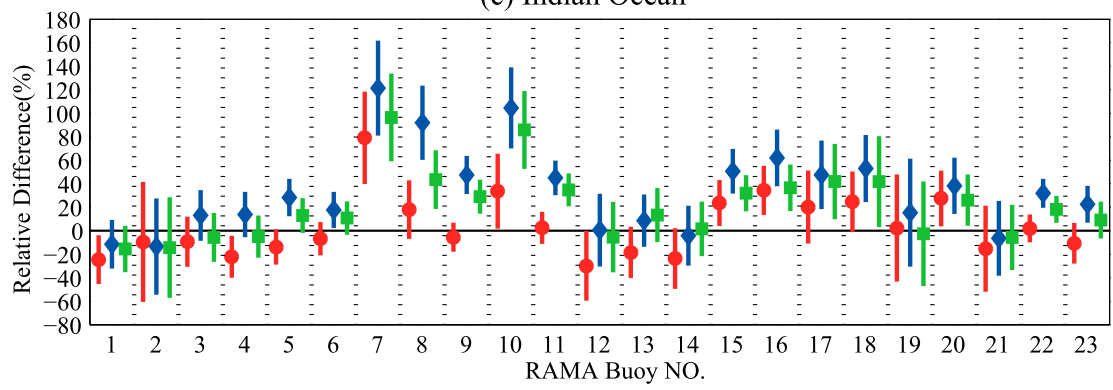

FIG. 6. Relative differences between the mean rainfall from the IMERG dataset and buoy data (red), the TMPA dataset and buoy data (blue), and the CMORPH dataset and buoy data (green) with respect to each mean buoy value for the (a) Pacific Ocean, (b) Atlantic Ocean, and (c) Indian Ocean. Each bar represents the $95 \%$ confidence interval of the mean difference.

satellite area average and buoy data for 16-, 32-, and 96-day averaging windows in three tropical basins. The 16-, 32-, and 96-day windows can be considered to be approximately half-monthly, monthly, and seasonal means, respectively. Gauge data were available intermittently, with relatively long gaps. All the available gauge and corresponding satellite data are averaged within each sequential N-day period. For TAO buoy 9 , for example, there are a total of eight 32-day periods with data available from the gauge. The mean precipitation rate at TAO buoy 9 is $9.98 \mathrm{mmday}^{-1}$, and the relative mean-square error is $24 \%, 44 \%$, and $28 \%$ for the IMERG, TMPA, and CMORPH, respectively (Table 3). For all three satellite datasets, the errors decrease as the averaging time increases, although there are some exceptions. For buoys showing high rainfall, IMERG typically has the smallest relative errors and TMPA has the largest relative errors for all 16-, 32-, and 96-day averaging periods in the tropical Pacific (Table 3). For low-rainfall areas, the errors increase for all three satellite datasets. Unlike in the Pacific, for buoys showing high rainfall, IMERG typically has the largest relative errors for all 16-, 32-, and 96-day averaging periods in the Atlantic (Table 4). For low-rainfall areas in the Atlantic, these errors are up to several hundred percent. Most of the Atlantic buoys are located in regions of low rainfall. IMERG shows the largest relative error among these three satellite datasets for most buoys with low rainfall for all different averaging periods. In the Indian Ocean, for buoys showing high rainfall, the relative errors between satellite and gauge are in the range $40 \%-120 \%, 20-110 \%$, and $10 \%-100 \%$ for 
TABLE 3. The relative mean square error (\%) between satellite and buoy data for different averaging windows (number of days) in the tropical Pacific. Satellite data are $0.5^{\circ} \times 0.5^{\circ}$ area averages. The value of $N$ is the number of periods used to estimate the sequential 32-day value.

\begin{tabular}{|c|c|c|c|c|c|c|c|c|c|c|c|}
\hline \multirow[b]{3}{*}{ Buoy No. } & \multirow[b]{3}{*}{$N$} & \multirow[b]{3}{*}{ Mean $\left(\mathrm{mm} \mathrm{day}^{-1}\right)$} & \multicolumn{9}{|c|}{ Averaging period (days) } \\
\hline & & & \multicolumn{3}{|c|}{16} & \multicolumn{3}{|c|}{32} & \multicolumn{3}{|c|}{96} \\
\hline & & & IMERG & TMPA & CMORPH & IMERG & TMPA & CMORPH & IMERG & TMPA & $\overline{\text { CMORPH }}$ \\
\hline 9 & 8 & 9.98 & 28 & 47 & 29 & 24 & 44 & 28 & 4 & 45 & 19 \\
\hline 5 & 8 & 7.40 & 26 & 47 & 38 & 14 & 39 & 27 & 5 & 34 & 23 \\
\hline 11 & 6 & 7.40 & 59 & 85 & 45 & 53 & 69 & 35 & 38 & 38 & 15 \\
\hline 3 & 16 & 6.13 & 50 & 59 & 57 & 41 & 44 & 42 & 26 & 36 & 34 \\
\hline 8 & 28 & 6.09 & 55 & 88 & 65 & 46 & 79 & 55 & 38 & 70 & 46 \\
\hline 4 & 11 & 5.75 & 45 & 60 & 52 & 26 & 54 & 45 & 24 & 55 & 48 \\
\hline 7 & 35 & 5.74 & 51 & 73 & 57 & 38 & 57 & 43 & 27 & 49 & 35 \\
\hline 6 & 30 & 5.25 & 70 & 91 & 78 & 49 & 74 & 61 & 34 & 64 & 50 \\
\hline 1 & 27 & 4.24 & 72 & 98 & 95 & 58 & 80 & 78 & 32 & 72 & 64 \\
\hline 2 & 18 & 3.59 & 65 & 99 & 97 & 51 & 87 & 84 & 38 & 76 & 76 \\
\hline 12 & 16 & 3.25 & 54 & 71 & 52 & 45 & 60 & 45 & 20 & 53 & 40 \\
\hline 10 & 9 & 1.97 & 67 & 50 & 53 & 26 & 27 & 32 & 10 & 22 & 14 \\
\hline 14 & 16 & 0.34 & 158 & 111 & 115 & 140 & 100 & 101 & 95 & 74 & 76 \\
\hline 13 & 12 & 0.18 & 136 & 125 & 238 & 123 & 109 & 193 & 95 & 82 & 121 \\
\hline
\end{tabular}

all 16-, 32-, and 96-day averages, respectively (Table 5). In the Indian Ocean, the performance of these three satellite datasets is rather mixed. IMERG shows the smallest relative errors for some gauges and for some averaging periods, and shows the largest relative errors for others. The same applies for TMPA and CMORPH.

The root-mean-square error (RMSE) in the multisatellite precipitation estimates can be decomposed into systematic and random components of error (Prakash et al. 2018). Systematic and random errors are defined as

$$
\begin{aligned}
\mathrm{RMSE}_{\text {system }} & =\sqrt{\frac{\sum_{i=1}^{N}\left(\mathrm{PS}_{i}^{*}-\mathrm{PB}_{i}\right)^{2}}{N},} \\
\mathrm{RMSE}_{\text {random }} & =\sqrt{\frac{\sum_{i=1}^{N}\left(\mathrm{PS}_{i}-\mathrm{PS}_{i}^{*}\right)^{2}}{N}},
\end{aligned}
$$

where $N$ is the number of days for which data were available for buoys in each basin, PS and PB are the

\begin{tabular}{|c|c|c|c|c|c|c|c|c|c|c|c|}
\hline \multirow[b]{3}{*}{ Buoy No. } & \multirow[b]{3}{*}{$N$} & \multirow[b]{3}{*}{$\operatorname{Mean}\left(\mathrm{mm} \mathrm{day}^{-1}\right)$} & \multicolumn{9}{|c|}{ Averaging period (days) } \\
\hline & & & \multicolumn{3}{|c|}{16} & \multicolumn{3}{|c|}{32} & \multicolumn{3}{|c|}{96} \\
\hline & & & IMERG & TMPA & CMORPH & IMERG & TMPA & CMORPH & IMERG & TMPA & CMORPH \\
\hline 12 & 26 & 7.55 & 75 & 56 & 60 & 62 & 47 & 47 & 50 & 37 & 35 \\
\hline 4 & 18 & 5.69 & 60 & 53 & 46 & 48 & 38 & 30 & 39 & 26 & 21 \\
\hline 5 & 23 & 5.05 & 72 & 67 & 65 & 55 & 46 & 48 & 31 & 32 & 30 \\
\hline 6 & 16 & 4.00 & 55 & 44 & 39 & 46 & 39 & 33 & 38 & 14 & 14 \\
\hline 11 & 21 & 2.40 & 105 & 61 & 64 & 78 & 43 & 37 & 61 & 25 & 15 \\
\hline 17 & 23 & 2.28 & 122 & 124 & 128 & 79 & 70 & 93 & 35 & 30 & 31 \\
\hline 3 & 31 & 1.96 & 106 & 105 & 101 & 78 & 84 & 82 & 41 & 39 & 45 \\
\hline 13 & 25 & 1.81 & 90 & 104 & 83 & 59 & 60 & 59 & 43 & 28 & 47 \\
\hline 14 & 15 & 1.63 & 114 & 95 & 104 & 98 & 78 & 91 & 76 & 56 & 72 \\
\hline 7 & 25 & 1.57 & 109 & 75 & 105 & 91 & 62 & 89 & 49 & 20 & 42 \\
\hline 18 & 34 & 1.28 & 194 & 192 & 174 & 143 & 133 & 123 & 72 & 54 & 51 \\
\hline 9 & 29 & 0.84 & 164 & 114 & 124 & 130 & 68 & 61 & 89 & 25 & 40 \\
\hline 8 & 16 & 0.64 & 244 & 177 & 230 & 137 & 84 & 112 & 80 & 41 & 61 \\
\hline 2 & 19 & 0.45 & 254 & 286 & 353 & 166 & 203 & 259 & 114 & 147 & 187 \\
\hline 15 & 32 & 0.18 & 631 & 365 & 410 & 465 & 263 & 295 & 250 & 115 & 122 \\
\hline 1 & 10 & 0.14 & 285 & 299 & 285 & 232 & 253 & 206 & 181 & 219 & 175 \\
\hline 10 & 16 & 0.00 & - & - & - & - & - & - & - & - & - \\
\hline 16 & 25 & 0.00 & - & - & - & - & - & - & - & - & - \\
\hline
\end{tabular}

TABle 4. As in Table 3, but for the Atlantic Ocean. 
TABLE 5. As in Table 3, but for the Indian Ocean.

\begin{tabular}{|c|c|c|c|c|c|c|c|c|c|c|c|}
\hline \multirow[b]{3}{*}{ Buoy No. } & \multirow[b]{3}{*}{$N$} & \multirow[b]{3}{*}{ Mean $\left(\mathrm{mm} \mathrm{day}^{-1}\right)$} & \multicolumn{9}{|c|}{ Averaging period (days) } \\
\hline & & & \multicolumn{3}{|c|}{16} & \multicolumn{3}{|c|}{32} & \multicolumn{3}{|c|}{96} \\
\hline & & & IMERG & TMPA & CMORPH & IMERG & TMPA & CMORPH & IMERG & TMPA & CMORPH \\
\hline 12 & 5 & 8.78 & 60 & 45 & 54 & 39 & 29 & 35 & 21 & 14 & 10 \\
\hline 22 & 17 & 7.28 & 40 & 48 & 39 & 28 & 37 & 26 & 16 & 35 & 22 \\
\hline 23 & 13 & 6.54 & 50 & 39 & 37 & 34 & 31 & 26 & 6 & 28 & 16 \\
\hline 19 & 6 & 5.98 & 125 & 118 & 118 & 73 & 67 & 63 & 9 & 18 & 8 \\
\hline 20 & 6 & 5.52 & 70 & 76 & 66 & 45 & 27 & 22 & 11 & 12 & 8 \\
\hline 1 & 13 & 5.51 & 74 & 72 & 67 & 47 & 46 & 46 & 37 & 25 & 30 \\
\hline 11 & 23 & 5.50 & 65 & 72 & 62 & 48 & 57 & 48 & 37 & 49 & 37 \\
\hline 3 & 25 & 5.43 & 114 & 109 & 102 & 89 & 83 & 77 & 65 & 54 & 52 \\
\hline 13 & 7 & 5.33 & 68 & 77 & 79 & 33 & 37 & 39 & 23 & 33 & 48 \\
\hline 9 & 19 & 5.14 & 43 & 75 & 56 & 35 & 64 & 46 & 29 & 53 & 29 \\
\hline 4 & 25 & 5.09 & 75 & 90 & 76 & 53 & 69 & 56 & 34 & 43 & 32 \\
\hline 21 & 10 & 5.07 & 46 & 53 & 50 & 27 & 35 & 29 & 15 & 22 & 17 \\
\hline 5 & 25 & 5.03 & 65 & 65 & 59 & 47 & 48 & 40 & 29 & 40 & 25 \\
\hline 6 & 24 & 4.72 & 60 & 68 & 57 & 46 & 51 & 39 & 29 & 34 & 27 \\
\hline 18 & 7 & 4.38 & 79 & 111 & 116 & 58 & 109 & 108 & 43 & 90 & 94 \\
\hline 14 & 8 & 3.98 & 50 & 45 & 49 & 41 & 27 & 35 & 24 & 17 & 28 \\
\hline 8 & 9 & 3.90 & 83 & 122 & 74 & 73 & 110 & 61 & 42 & 111 & 43 \\
\hline 16 & 24 & 3.88 & 101 & 157 & 106 & 86 & 144 & 98 & 70 & 121 & 82 \\
\hline 15 & 26 & 3.72 & 117 & 127 & 91 & 89 & 116 & 75 & 70 & 103 & 60 \\
\hline 10 & 16 & 3.65 & 134 & 167 & 152 & 124 & 159 & 143 & 106 & 141 & 114 \\
\hline 17 & 11 & 3.02 & 109 & 109 & 126 & 88 & 74 & 91 & 58 & 59 & 68 \\
\hline 2 & 7 & 2.53 & 110 & 54 & 67 & 85 & 33 & 41 & 56 & 8 & 8 \\
\hline 7 & 18 & 1.87 & 190 & 231 & 202 & 174 & 206 & 174 & 71 & 93 & 77 \\
\hline
\end{tabular}

precipitation estimates from multisatellite and moored buoys, respectively. The PS* is defined by a linear regression model PS ${ }^{*}=a \times \mathrm{PS}+b$, in which $a$ and $b$ are the slope and intercept, respectively. The systematic and random errors computed from daily mean precipitation from three satellite products and buoys for all three ocean basins are shown in Table 6. For all three ocean basins, the correlations of daily precipitation between the satellite products and the buoy data are similar. Decomposition of the error shows that the proportion of systematic error is smallest in the tropical Pacific and the largest in the tropical Atlantic for all three satellite products. In the Pacific and Indian Oceans, the random component contributes more to the RMSE than the systematic component, while in the Atlantic Ocean, the contributions of the systematic and random components to the RMSE are rather similar. Prakash et al. (2018) found that the systematic error from hourly IMERG precipitation estimates compared with buoy data for the period March 2014 December 2015 contributes $15 \%$ and $13 \%$ to the RMSE for the Arabian Sea and the Bay of Bengal, respectively. The systematic error from daily mean IMERG precipitation in the Indian Ocean in this study is larger than that from hourly IMERG precipitation reported by Prakash et al. (2018).

The fluctuations in the biases were different for different rainfall rates. We checked the results as a function of the rainfall rate by placing the rainfall parameters into eight bins defined by the rainfall at each buoy and recalculating the mean differences in terms of the percentage time for which that rainfall occurred. The rainfall PDFs for the Pacific Ocean (Fig. 7) showed that less light rainfall (0-1 mm day ${ }^{-1}$, "no rainfall" was not included) was observed by all three satellite rainfall products than at the buoys except for TAO buoy 10 . For rainfall between 1 and $3 \mathrm{~mm}^{-1 a y}{ }^{-1}$, more rainfall was found for all three satellite rainfall products than for the buoy data, excluding TAO buoy 10 . The rain gauge data could also be subject to bias, for example, by wind. We examined the surface winds influencing the buoys using ASCAT (Bentamy and Fillon 2012) wind data. The data obtained at TAO buoy 10 was not especially influenced by high wind (not shown). The differences in values between all three satellite precipitation products and TAO buoy 10 are therefore not due to wind-induced errors. The PDFs for the Pacific Ocean indicated that all three satellite rainfall products overestimated the rainfall, and that the TMPA data overestimated it the most. Unlike for the Pacific Ocean, most of the buoys in the Atlantic Ocean were in regions of low rainfall. The rainfall PDFs for the Atlantic Ocean (Fig. 8) showed more light rainfall in all three satellite rainfall products than in the buoy data for the high-rainfall regions, unlike for the Pacific Ocean. Furthermore, PIRATA buoys 4, 5, 6, and 12 are located at the Atlantic ITCZ. Area-averaged IMERG 
rainfall data centered on these four buoys showed less rainfall at rates $>10 \mathrm{~mm} \mathrm{day}^{-1}$ than was found in the buoy data, thus explaining why the IMERG data underestimates rainfall, as shown in Fig. 5b. In Fig. 5c for the Indian Ocean, the correlation coefficients were relatively low for the relationships between the buoy data and all three satellite datasets. The rainfall PDFs for the buoy and satellite measurements were less consistent for the Indian Ocean than for the Pacific and Atlantic oceans (Fig. 9). The basinwide rainfall PDFs indicated that all three satellite rainfall products measured more light rainfall than was indicated by the buoy data for the Indian Ocean. However, the rainfall PDFs for individual buoys indicate that the satellite measurements underestimated rainfall at some locations and overestimated it at others. RAMA buoy 21 measured about $20 \%$ more light rain than was indicated by all three area-averaged satellite datasets, and RAMA buoys 7 and 10 measured about $20 \%$ less light rainfall than was indicated by all three area-averaged satellite datasets. There was a tendency for less light rainfall to be measured in the TMPA dataset than in the IMERG and CMORPH datasets for all three basins. The PDFs for rainfall for the buoy and satellite measurements for the high-rainfall regions in the different basins were not identical, suggesting that the biases for the three datasets were different for different regions.

This paper evaluated the biases between different satellite estimates and the rain gauge data. However, the rain gauge measurement itself can be biased. Wind-induced undercatchment errors can be substantial for unprotected siphon-type rain gauges (Serra and McPhaden 2003). These errors could range from $10 \%$ to $50 \%$ for wind speeds typical at the Pacific and Atlantic buoys. After the wind correction, the buoy monthly rainfall increase by $14 \%$ (Serra and McPhaden 2003). Though important for mean rates of rainfall, the wind-induced undercatchment errors are not a significant source of the variance. The correlation coefficients for the windcorrected comparisons remain roughly the same as those observed for the uncorrected data, with correlations at small spatial scales showing some improvement over the uncorrected data (Serra and McPhaden 2003). Since the rain gauges are more than likely to underestimate actual rainfall, the overestimation of satellite data in the tropical Pacific Ocean could be less than we have described herein, while the underestimation of satellite data in the tropical Atlantic Ocean could be even larger.

\section{c. Comparison of multisatellite precipitation data from TRMM and GPM}

In our final piece of analysis we compared the mean IMERG rainfall with those from TMPA and CMORPH. 

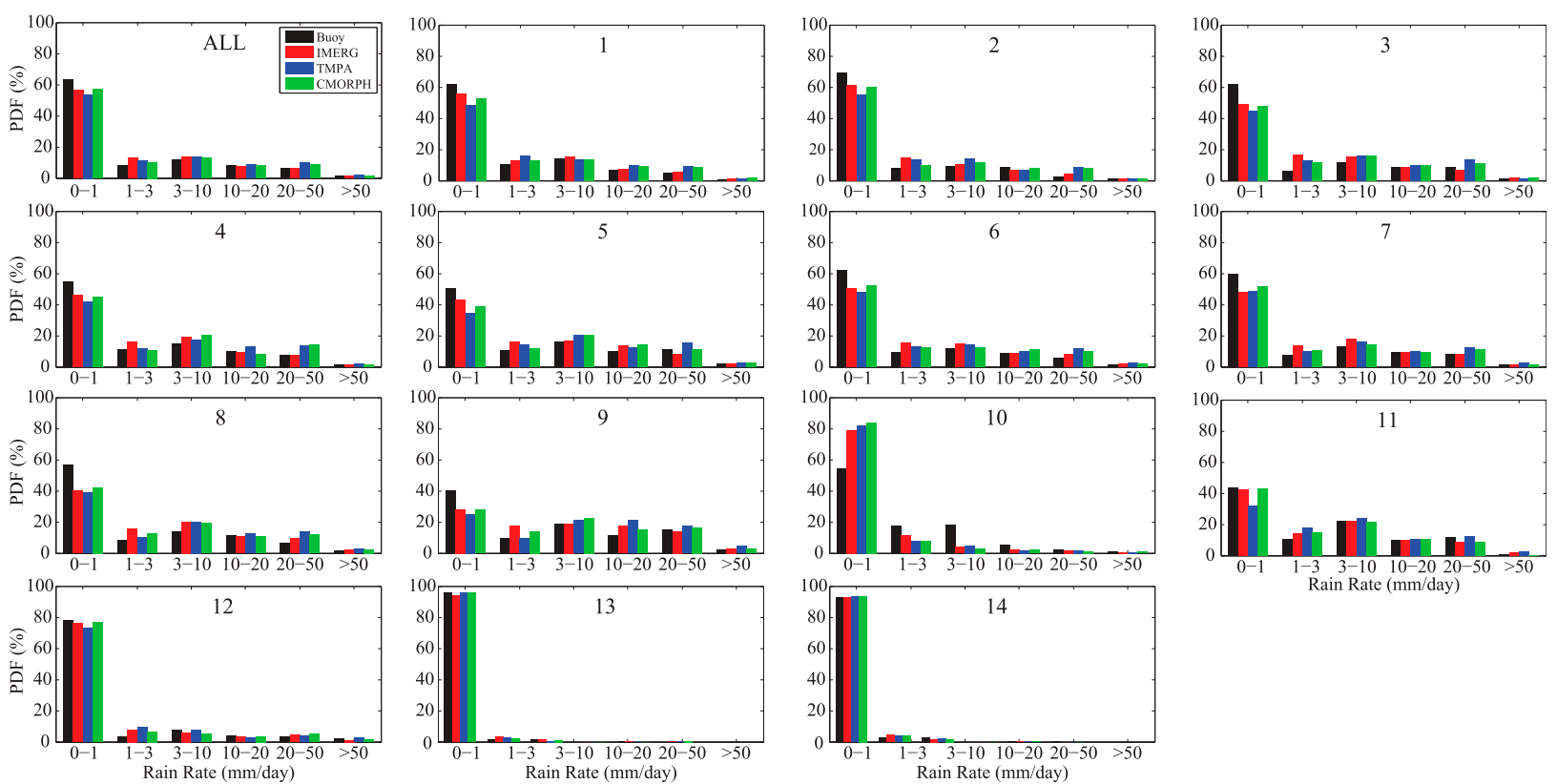

FIG. 7. PDFs for daily rainfall from all and each TAO buoy (black), the IMERG dataset (red), the TMPA dataset (blue), and the CMORPH dataset (green) for the Pacific Ocean

Differences in the spatial resolutions of the three data products meant that the IMERG and CMORPH products needed to be regridded to match the TMPA grid before comparisons could be made. Using a simple box averaging method, average values were obtained for a $0.5^{\circ} \times 0.5^{\circ}$ grid. The geographical variations in the bias are shown in Fig. 10. In Fig. 10a we note that less rainfall was measured in the IMERG dataset than in the TMPA dataset for all the tropical oceans. Large negative differences between the IMERG and TMPA datasets were found in high-rainfall areas in the tropics, including for the Pacific and Atlantic ITCZs, the Pacific warm pool, the SPCZ, the Indian Ocean, and the Gulf Stream. The differences between the IMERG and TMPA data were much smaller over land than over the ocean because the IMERG and TMPA datasets used GPCC gauge adjustment to correct bias. The pattern of systematic differences in Fig. 10a is similar to the pattern of differences between the IMERG version 03 products and TMPA data, as shown in Liu (2016).

The differences between the CPMORH and TMPA rainfall data were smaller than the differences between the IMERG and TMPA rainfall data over the ocean but larger over the land (Fig. 10b). The CMORPH dataset showed relatively low rainfall for the Warm Pool, Atlantic ITCZ, and Gulf Stream, but high rainfall for some parts of the Pacific ITCZ and the subtropical oceans. The rainfall over land, especially over South America, was generally lower in the CMORPH dataset than in the TMPA dataset. The differences between the
CMORPH and TMPA datasets over land may have been caused by differences in the schemes used to correct bias. The current version of the CMORPH dataset is bias-corrected against the CPC daily gauge data over land, whereas the IMERG and TMPA datasets are biascorrected against monthly GPCC gauge data. It was concluded that bias in the CMORPH satellite precipitation estimates over land during the warm season (May-September) has been removed completely, but that the CMORPH dataset tends to underestimate precipitation during the cold season (October-April) (Xie et al. 2017).

The differences between the IMERG and CMORPH rainfall data (Fig. 10c) over the oceans show similar geographical variations to the differences between the IMERG and TMPA rainfall data over the oceans (Fig. 10a). The rates of rainfall in the IMERG dataset were lower than those in the CMORPH data for high rainfall areas in the tropics. The differences between the IMERG and CMORPH data were smaller than between the IMERG and TMPA data for the Warm Pool, the SPCZ, and Atlantic ITCZ. The differences between the IMERG and CMORPH data were smaller than between the IMERG and TMPA data for the Kuroshio, the Kuroshio Extension region, and some Pacific ITCZ regions. This again indicates that the differences in the three datasets vary for regions of high rainfall. Since the differences between the IMERG and TMPA data were small over land, and the CMORPH data showed lower rainfall than in the TMPA data over South America and 

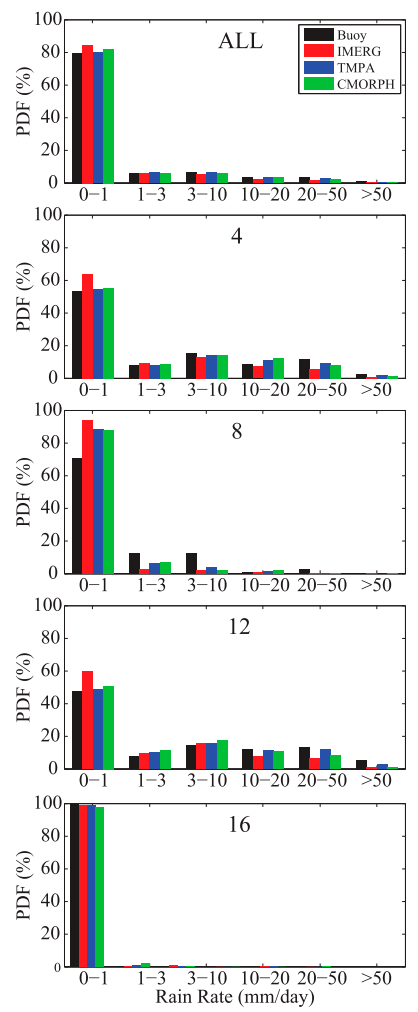
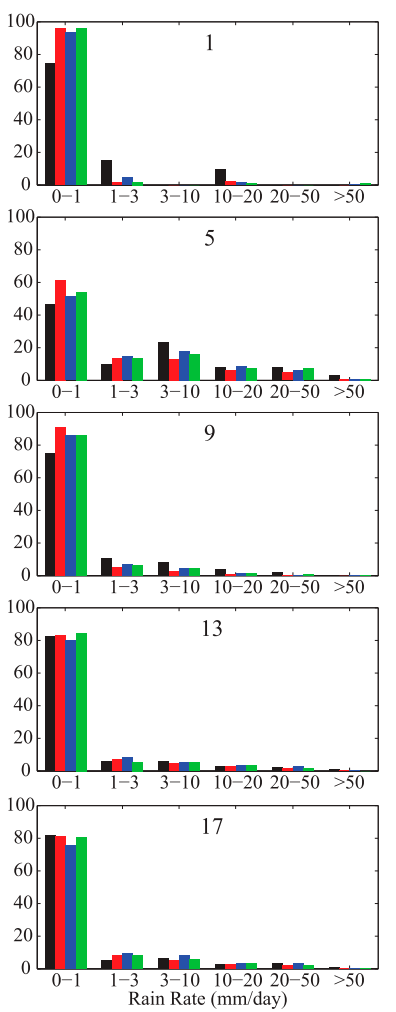
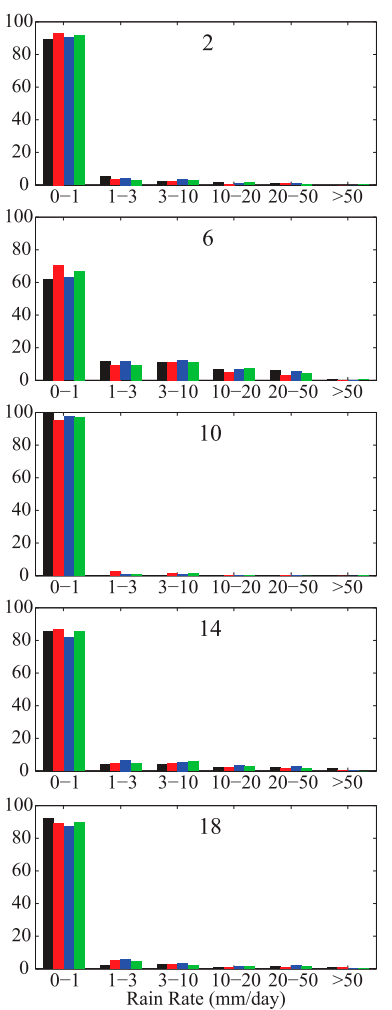
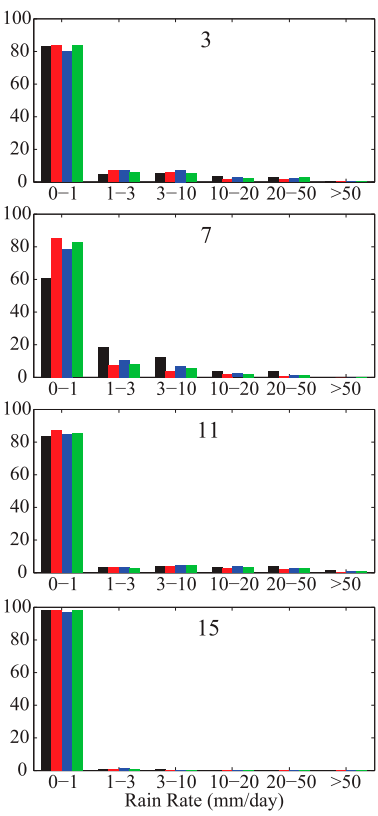

FIG. 8. As in Fig. 7, but for the Atlantic Ocean.

some regions in Africa, the rates of rainfall in these regions were generally lower in the CMORPH data than in the IMERG data, as expected.

\section{Summary and discussion}

We have compared three satellite precipitation datasets for the tropics with in situ rain gauge data obtained from ocean buoys for the period 1 April 2014-30 April 2017. IMERG version 05 early, late, and final run products were compared with the data from the rain gauges. For all three tropical oceans, the mean IMERG final run rainfall rates are the lowest and the early run rainfall rates are the highest. All three IMERG products overestimated rainfall over the tropical Pacific, and the IMERG final run products matched the gauge data better than the other two products. Over the tropical Atlantic, all three IMERG products underestimated the rainfall, but the IMERG early run products matched the gauge data better than the other two products. In the Indian Ocean, the IMERG products underestimated the rainfall for some gauges but overestimated it for others.

The relationships between the long-time mean gauge data and the three sets of satellite data for three tropical oceans were similar in some ways and different in others. For all three tropical oceans, all three satellite precipitation datasets were statistically significantly linearly correlated with the gauge data. The TMPA data systematically overestimated the precipitation over all three oceans. The regression coefficients for the relationships between the satellite and buoy data were calculated, the highest being for the TMPA data and the lowest for the IMERG data, for all three tropical oceans. The correlations between the mean gauge data and three sets of satellite precipitation data were less good for the Indian Ocean than for the Pacific or Atlantic oceans.

The rainfall PDFs indicate that light rainfall is underestimated by all three satellite rainfall products for the high-rainfall region in the tropical Pacific Ocean, but that light rainfall is overestimated by all three satellite rainfall products for the high-rainfall region in the Atlantic ITCZ. For the Indian Ocean, the basinwide rainfall PDFs indicate that light rainfall is overestimated by all three satellite rainfall products. The rainfall PDFs for individual buoys indicate that rainfall is underestimated by satellite measurements in some locations but overestimated in others. Light rainfall is underestimated by the TMPA dataset compared with the IMERG and CMORPH datasets for all three basins. For high-rainfall regions, the differences between the buoy measurements and IMERG daily data are 

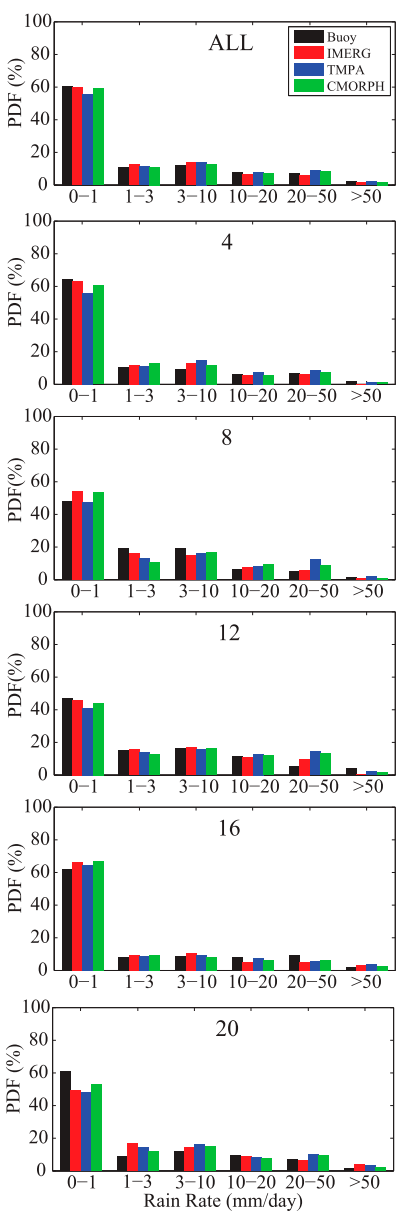
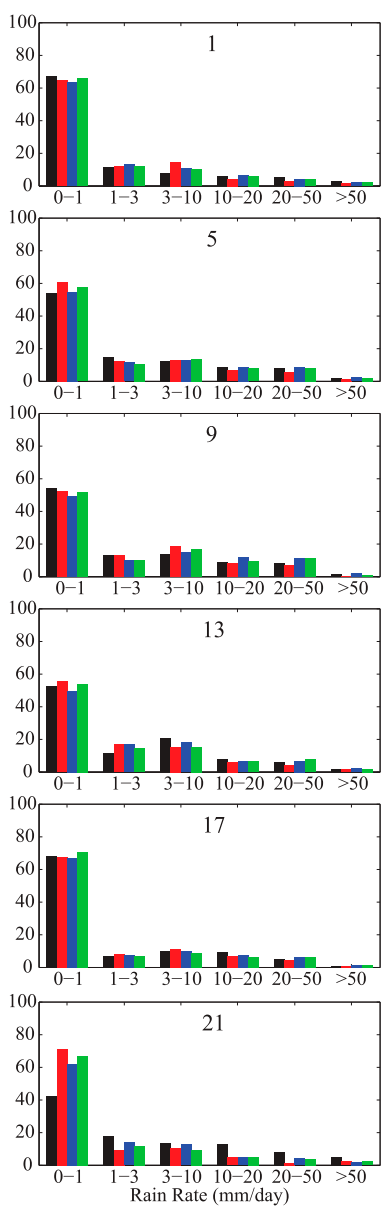
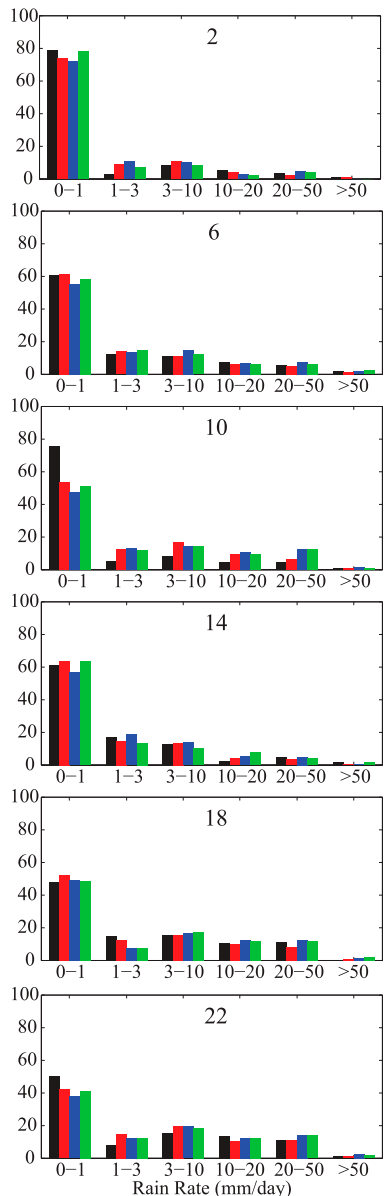
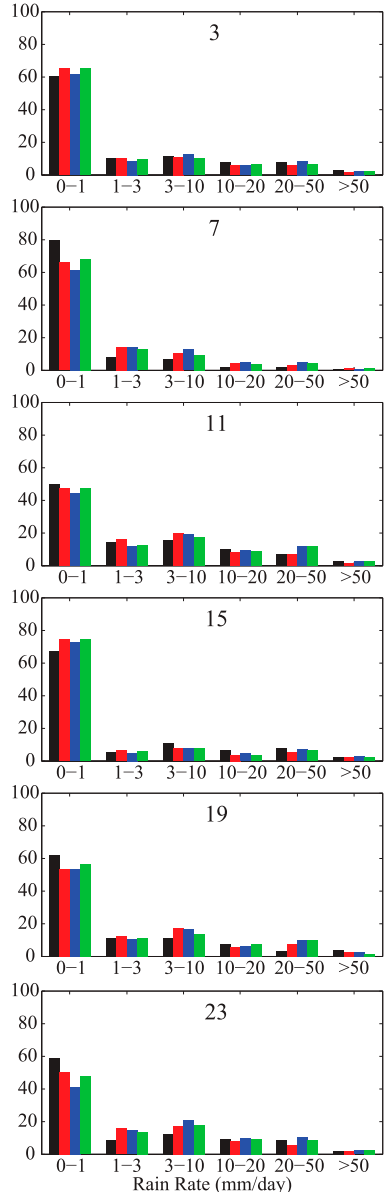

FIG. 9. As in Fig. 7, but for the Indian Ocean.

smaller than the differences between the buoy measurements and the other satellite rainfall datasets for the tropical Pacific and Indian oceans, but these differences were larger than the differences between the buoy measurements and the other satellite rainfall datasets for the tropical Atlantic Ocean. This indicates that for high-rainfall regions the IMERG dataset provides a more accurate estimate than mean precipitation over the tropical Pacific and Indian oceans but a less accurate estimate of mean precipitation over the tropical Atlantic Ocean than the other satellite datasets.

When comparing satellite estimates with gauges using area-averaged rainfall over areas ranging from $0.25^{\circ} \times$ $0.25^{\circ}$ to $2.5^{\circ} \times 2.5^{\circ}$ square boxes centered on buoy locations, the differences between satellite and gauge measurements were in general not sensitive to changes in averaging area except in some cases where buoys are located in regions with different rainfall characteristics from adjacent regions. For all three satellite precipitation datasets, the errors decrease as the averaging time increases, with some exceptions. The relative errors are higher for buoys located in low-rainfall areas. For buoys in high-rainfall areas in the tropical Pacific, IMERG typically shows the smallest relative errors and TMPA shows the largest relative errors for all 16-, 32-, and 96-day averaging periods. In the tropical Atlantic, IMERG shows the largest relative errors among the three satellite datasets for most buoys with low rainfall for all different averaging periods. By decomposing satellite and gauge measurements into systematic and random-error components, we found that the proportion of systematic error is considerably larger in the tropical Atlantic than in the Pacific and Indian Oceans. The reason for this is partly because most of the Atlantic buoys are located in regions of low rainfall. The relative errors are greater for low- than for high-rainfall areas.

We have evaluated the biases between different satellite estimates and the rain gauge data, and note that rain gauge measurement can also be biased. The wind-induced undercatchment errors can be substantial for unprotected siphon-type rain gauges (Serra and McPhaden 2003). 
(a) Difference between IMERG and TMPA

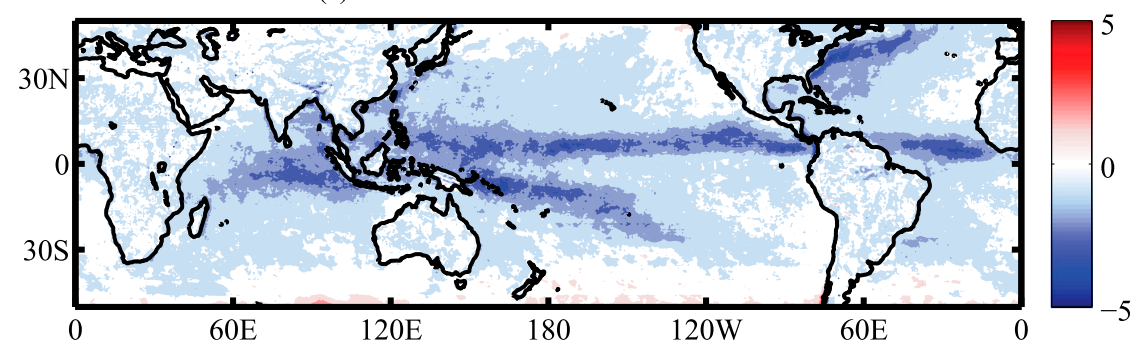

(b) Difference between CMORPH and TMPA

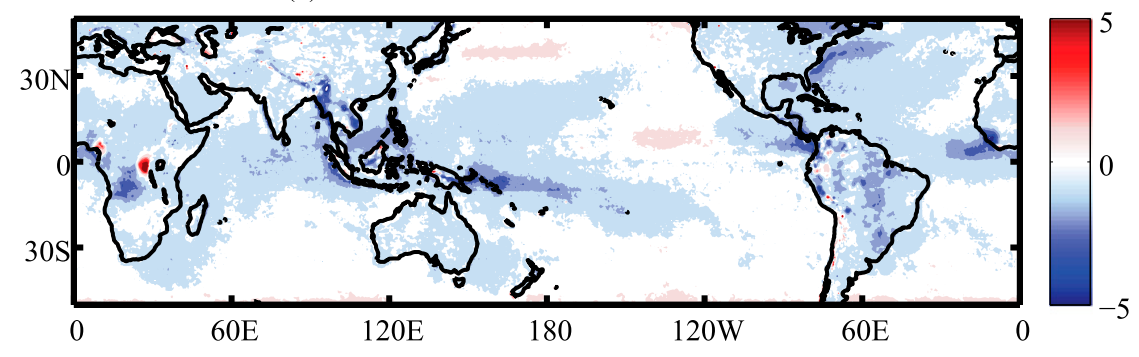

(c) Difference between IMERG and CMORPH

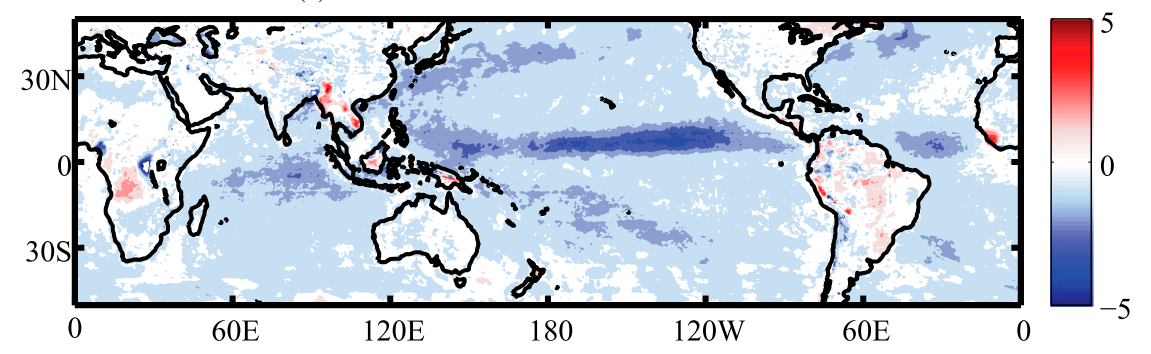

FIG. 10. Maps of the rainfall differences $\left(\mathrm{mm} \mathrm{day}^{-1}\right.$ ) between the (a) IMERG and TMPA datasets (IMERG minus TMPA), (b) CMORPH and TMPA datasets (CMORPH minus TMPA), and (c) IMERG and CMORPH (IMERG minus CMORPH) datasets for the period 1 Apr 2014-30 Apr 2017

Since the rain gauges are more than likely to underestimate actual rainfall, the overestimation of satellite data in the tropical Pacific Ocean could be less than we describe, while the underestimation of satellite data in the tropical Atlantic Ocean could be even greater.

For the Indian Ocean, all three rainfall satellite datasets overestimate rainfall at some gauges and underestimate it at others. One of the possible reasons may be the seasonal variations of convective and stratiform precipitation over the tropical Indian Ocean. Convective precipitation is essentially associated with small horizontal spread high precipitation rates while stratiform precipitation is characterized by widespread low precipitation rates (Schumacher and Houze 2003). The fraction of stratiform precipitation over the high-rainfall regions, where most of the RAMA buoys are located, is relatively less during the monsoon season than other seasons (Prakash and Gairola 2014). All three satellite rainfall datasets tend to overestimate low rainfall rates and underestimate high rainfall rates in the Tropical Indian Ocean, which may cause negative discrepancies compared with actual rainfall during the monsoon season. The rain gauges are likely to underestimate actual rainfall. When the underestimated satellite rainfall is lower than the underestimated gauge rainfall, there is negative bias between satellite and gauge rainfall. Data from all the gauges were intermittent. Satellite rainfall datasets observed at different seasons therefore may cause positive or negative bias compared with gauge rainfall.

Acknowledgments. Funding for this study was provided by the National Natural Science Foundation of China (Grants 41722601, 41690121, and 41690120), the Strategic Priority Research Program of the Chinese Academy of Sciences (Grant XDA20060501), and the Zhejiang Provincial NSFC (Grant R15D060003). The TMPA 3B42 and IMERG data used were obtained from 
the NASA Goddard Earth Sciences Data and Information Services Center. Version 1.0 CMORPH data are available at ftp.cpc.ncep.noaa.gov/precip/CMORPH_ V1.0. Rain gauge data were acquired from NOAA PMEL. We would also like to acknowledge three anonymous reviewers for their helpful comments and suggestions on the manuscript.

\section{REFERENCES}

Bentamy, A., and D. C. Fillon, 2012: Gridded surface wind fields from Metop/ASCAT measurements. Int. J. Remote Sens., 33, 1729-1754, https://doi.org/10.1080/01431161.2011.600348.

Bowman, K. P., 2005: Comparison of TRMM precipitation retrievals with rain gauge data from ocean buoys. J. Climate, $\mathbf{1 8}$, 178-190, https://doi.org/10.1175/JCLI3259.1.

$\longrightarrow$ A. B. Phillips, and G. R. North, 2003: Comparison of TRMM rainfall retrievals with rain gauge data from the TAO/TRITON buoy array. Geophys. Res. Lett., 30, 1757, https://doi.org/ 10.1029/2003GL017552.

— C. R. Homeyer, and D. G. Stone, 2009: A comparison of oceanic precipitation estimates in the tropics and subtropics. J. Appl. Meteor. Climatol., 48, 1335-1344, https://doi.org/10.1175/ 2009JAMC2149.1.

Burdanowitz, J., C. Klepp, S. Bakan, and S. A. Buehler, 2017: Simulation of ship-track versus satellite-sensor differences in oceanic precipitation using an island-based radar. Remote Sens., 9, 593, https://doi.org/10.3390/rs9060593.

Hayes, S. P., L. J. Mangum, J. Picaut, A. Sumi, and K. Takeuchi, 1991: TOGA-TAO: A moored array for real-time measurements in the tropical Pacific Ocean. Bull. Amer. Meteor. Soc., 72, 339-347, https://doi.org/10.1175/1520-0477(1991)072<0339: TTAMAF $>2.0 . \mathrm{CO} ; 2$.

Hou, A. Y., and Coauthors, 2014: The Global Precipitation Measurement mission. Bull. Amer. Meteor. Soc., 95, 701-722, https://doi.org/10.1175/BAMS-D-13-00164.1.

Hsu, K.-L., X. Gao, S. Sorooshian, and V. Gupta, 1997: Precipitation estimation from remotely sensed information using artificial neural networks. J. Appl. Meteor., 36, 1176-1190, https://doi.org/ 10.1175/1520-0450(1997)036<1176:PEFRSI >2.0.CO;2.

Huffman, G. J., and Coauthors, 2007: The TRMM Multisatellite Precipitation Analysis (TMPA): Quasi-global, multiyear, combinedsensor precipitation estimates at fine scales. J. Hydrometeor., $\mathbf{8}$, 38-55, https://doi.org/10.1175/JHM560.1.

— R. F. Adler, D. T. Bolvin, and E. J. Nelkin, 2010: The TRMM Multisatellite Precipitation Analysis (TMPA). Satellite Rainfall Applications for Surface Hydrology, F. Hossain and M. Gebremichael, Eds., Springer-Verlag, 3-22.

__ , and Coauthors, 2015: The Climate Data Guide: TRMM: Tropical Rainfall Measuring Mission. NCAR, https:// climatedataguide.ucar.edu/climate-data/trmm-tropical-rainfallmeasuring-mission.

_ surement (GPM) Integrated Multi-SatellitE Retrievals for GPM (IMERG). Algorithm Theoretical Basis Doc., version 5.1,34 pp., https://pmm.nasa.gov/sites/default/files/document_files/ IMERG_ATBD_V5.1.pdf.

, D. T. Bolvin, and E. J. Nelkin, 2017b: Integrated MultisatellitE Retrievals for GPM (IMERG) technical documentation. NASA Tech. Doc., 54 pp., https://pmm.nasa.gov/sites/ default/files/document_files/IMERG_technical_doc_3_22_17.pdf.
,,,--- and E. F. Stocker, 2017c: V05 IMERG Early and Late Run release notes. NASA/GSFC, 2 pp., https://pmm.nasa.gov/sites/ default/files/document_files/IMERG_EarlyLateRun_V05_release_ notes-rev.pdf.

$\longrightarrow,-,-,-$, and J. Tan, 2017d: V05 IMERG Final Run release notes. NASA/GSFC, 8 pp., https://pmm.nasa.gov/sites/ default/files/document_files/IMERG_FinalRun_V05_release_ notes-rev3.pdf.

Joyce, R. J., and P. Xie, 2011: Kalman filter-based CMORPH. J. Hydrometeor., 12, 1547-1563, https://doi.org/10.1175/JHMD-11-022.1.

_ J. E. Janowiak, P. A. Arkin, and P. Xie, 2004: CMORPH: A method that produces global precipitation estimates from passive microwave and infrared data at high spatial and temporal resolution. J. Hydrometeor., 5, 487-503, https://doi.org/ 10.1175/1525-7541(2004)005<0487:CAMTPG >2.0.CO;2.

Kidd, C., D. R. Kniveton, M. C. Todd, and T. J. Bellerby, 2003: Satellite rainfall estimation using combined passive microwave and infrared algorithms. J. Hydrometeor., 4, 1088-1104, https://doi.org/ 10.1175/1525-7541(2003)004<1088:SREUCP >2.0.CO;2.

Kubota, T., and Coauthors, 2007: Global precipitation map using satellite-borne microwave radiometers by the GSMaP Project: Production and validation. IEEE Trans. Geosci. Remote Sens., 45, 2259-2275, https://doi.org/10.1109/TGRS.2007.895337.

Kuligowski, R. J., 2002: A self-calibrating real-time GOES rainfall algorithm for short-term rainfall estimates. J. Hydrometeor., 3, 112-130, https://doi.org/10.1175/1525-7541(2002)003<0112: ASCRTG $>2.0 . \mathrm{CO} ; 2$.

Liu, X., P. Chang, J. Kurian, R. Saravanan, and X. Lin, 2018: Satellite observed precipitation response to ocean mesoscale eddies. J. Climate, 31, 6879-6895, https://doi.org/10.1175/ JCLI-D-17-0668.1.

Liu, Z., 2016: Comparison of Integrated Multisatellite Retrievals for GPM (IMERG) and TRMM Multisatellite Precipitation Analysis (TMPA) monthly precipitation products: Initial results. J. Hydrometeor., 17, 777-790, https://doi.org/10.1175/ JHM-D-15-0068.1.

McPhaden, M. J., and Coauthors, 1998: The tropical ocean-global atmosphere observing system: A decade of progress. J. Geophys. Res., 103, 14 169-14240, https://doi.org/10.1029/97JC02906.

_ , and Coauthors, 2009: RAMA: The Research Moored Array for African-Asian-Australian Monsoon Analysis and Prediction. Bull. Amer. Meteor. Soc., 90, 459-480, https://doi.org/ 10.1175/2008BAMS2608.1.

Murali Krishna, U. V., S. K. Das, S. M. Deshpande, S. L. Doiphode, and G. Pandithurai, 2017: The Assessment of Global Precipitation Measurement estimates over the Indian Subcontinent. Earth Space Sci., 4, 540-553, https://doi.org/10.1002/2017EA000285.

Prakash, S., and R. M. Gairola, 2014: Validation of TRMM-3B42 precipitation product over the tropical Indian Ocean using rain gauge data from the RAMA buoy array. Theor. Appl. Climatol., 115, 451-460, https://doi.org/10.1007/s00704-013-0903-3. C. Mahesh, and R. M. Gairola, 2013: Comparison of TRMM Multi-satellite Precipitation Analysis (TMPA)-3B43 version 6 and 7 products with rain gauge data from ocean buoys. Remote Sens. Lett., 4, 677-685, https://doi.org/10.1080/2150704X.2013.783248.

- M. R. Kumar, S. Mathew, and R. Venkatesan, 2018: How accurate are satellite estimates of precipitation over the north Indian Ocean? Theor. Appl. Climatol., 134, 467-475, https:// doi.org/10.1007/s00704-017-2287-2.

Qin, Y., Z. Chen, Y. Shen, S. Zhang, and R. Shi, 2014: Evaluation of satellite rainfall estimates over the Chinese mainland. Remote Sens., 6, 11 649-11 672, https://doi.org/10.3390/rs61111649. 
Sapiano, M. R. P., and P. A. Arkin, 2009: An intercomparison and validation of high-resolution satellite precipitation estimates with 3-hourly gauge data. J. Hydrometeor., 10, 149-166, https:// doi.org/10.1175/2008JHM1052.1.

Schumacher, C., and R. A. Houze Jr., 2003: Stratiform rain in the tropics as seen by the TRMM precipitation radar. J. Climate, 16, 1739-1756, https://doi.org/10.1175/15200442(2003)016<1739:SRITTA > 2.0.CO;2.

Serra, Y. L., and M. J. McPhaden, 2003: Multiple time- and spacescale comparisons of ATLAS buoy rain gauge measurements with TRMM satellite precipitation measurements. J. Appl. Meteor., 42, 1045-1059, https://doi.org/10.1175/1520-0450(2003) 042<1045:MTASCO > 2.0.CO;2.

, and —_, 2004: In situ observations of diurnal variability in rainfall over the tropical Pacific and Atlantic Oceans. J. Climate, 17, 3496-3509, https://doi.org/10.1175/1520-0442(2004)017<3496: ISOODV $>2.0 . \mathrm{CO} ; 2$.

—- P. A'Hearn, H. P. Freitag, and M. J. McPhaden, 2001: ATLAS self-siphoning rain gauge error estimates. J. Atmos. Oceanic Technol., 18, 1989-2002, https://doi.org/10.1175/ 1520-0426(2001)018<1989:ASSRGE>2.0.CO;2.

Sorooshian, S., K.-L. Hsu, X. Gao, H. V. Gupta, B. Imam, and D. Braithwaite, 2000: Evaluation of PERSIANN system satellite-based estimates of tropical rainfall. Bull. Amer. Meteor. Soc., 81, 2035-2046, https://doi.org/10.1175/1520-0477(2000) $081<2035$ :EOPSSE $>2.3$.CO;2.

Tang, G., Y. Ma, D. Long, L. Zhong, and Y. Hong, 2016: Evaluation of GPM Day-1 IMERG and TMPA Version-7 legacy products over Mainland China at multiple spatiotemporal scales. J. Hydrol., 533, 152-167, https://doi.org/10.1016/ j.jhydrol.2015.12.008.

Tao, W. K., E. A. Smith, and R. A. Houze Jr., 2007: The Fourth TRMM Latent Heating Workshop. Bull. Amer. Meteor. Soc., 88, 1255-1259, https://doi.org/10.1175/BAMS-88-8-1245.

Wang, C., G. Tang, Z. Han, X. Guo, and Y. Hong, 2018: Global intercomparison and regional evaluation of GPM IMERG Version-03, Version-04 and its latest Version-05 precipitation products: Similarity, difference and improvements. J. Hydrol., 564, 342-356, https://doi.org/10.1016/j.jhydrol.2018.06.064.

Wang, R., J. Chen, and X. Wang, 2017: Comparison of IMERG Level-3 and TMPA 3B42V7 in estimating typhoon-related heavy rain. Water, 9, 276, https://doi.org/10.3390/w9040276.

Xie, P., R. Joyce, S. Wu, S. Yoo, Y. Yarosh, F. Sun, and R. Lin, 2017: Reprocessed, bias-corrected CMORPH global high-resolution precipitation estimates from 1998. J. Hydrometeor., 18, 16171641, https://doi.org/10.1175/JHM-D-16-0168.1. 